\title{
Dynamics of particulate organic carbon flux in a global ocean model
}

\author{
I. D. Lima, P. J. Lam, and S. C. Doney \\ Woods Hole Oceanographic Institution, Department of Marine Chemistry \& Geochemistry, Woods Hole MA, USA \\ Correspondence to: I. Lima (ivan@whoi.edu)
}

Received: 21 August 2013 - Published in Biogeosciences Discuss.: 6 September 2013

Revised: 2 January 2014 - Accepted: 7 January 2014 - Published: 27 February 2014

\begin{abstract}
The sinking of particulate organic carbon (POC) is a key component of the ocean carbon cycle and plays an important role in the global climate system. However, the processes controlling the fraction of primary production that is exported from the euphotic zone (export ratio) and how much of it survives respiration in the mesopelagic to be sequestered in the deep ocean (transfer efficiency) are not well understood. In this study, we use a three-dimensional, coupled physical-biogeochemical model (CCSM-BEC; Community Climate System Model-ocean Biogeochemical Elemental Cycle) to investigate the processes controlling the export of particulate organic matter from the euphotic zone and its flux to depth. We also compare model results with sediment trap data and other parameterizations of POC flux to depth to evaluate model skill and gain further insight into the causes of error and uncertainty in POC flux estimates. In the model, export ratios are mainly a function of diatom relative abundance and temperature while absolute fluxes and transfer efficiency are driven by mineral ballast composition of sinking material. The temperature dependence of the POC remineralization length scale is modulated by denitrification under low $\mathrm{O}_{2}$ concentrations and lithogenic (dust) fluxes. Lithogenic material is an important control of transfer efficiency in the model, but its effect is restricted to regions of strong atmospheric dust deposition. In the remaining regions, $\mathrm{CaCO}_{3}$ content of exported material is the main factor affecting transfer efficiency. The fact that mineral ballast composition is inextricably linked to plankton community structure results in correlations between export ratios and ballast minerals fluxes (opal and $\mathrm{CaCO}_{3}$ ), and transfer efficiency and diatom relative abundance that do not necessarily reflect ballast or direct ecosystem effects, respectively. This suggests that it might be difficult to differentiate between ecosystem and ballast effects in observations. The model's skill in reproducing sediment trap observations is equal to or better
\end{abstract}

than that of other parameterizations. However, the sparseness and relatively large uncertainties of sediment trap data makes it difficult to accurately evaluate the skill of the model and other parameterizations. More POC flux observations, over a wider range of ecological regimes, are necessary to thoroughly evaluate and test model results and better understand the processes controlling POC flux to depth in the ocean.

\section{Introduction}

The transfer of carbon from the upper ocean to deep waters through the sinking of particulate biogenic material (biological pump, Volk and Hoffert, 1985) is a major component of the ocean carbon cycle and plays an important role in regulating atmospheric $\mathrm{CO}_{2}$ levels (Archer et al., 2000; Siegenthaler et al., 2005). However, the processes controlling the fraction of primary production that is exported from the euphotic zone (export ratio) and how much of it survives respiration in the mesopelagic to be sequestered in the deep ocean (transfer efficiency) are not well understood (Boyd and Trull, 2007). Biogenic minerals $\left(\mathrm{CaCO}_{3}\right.$ and opal) are thought to be important controlling factors (ballast hypothesis) by increasing the density of sinking particles and/or providing protection against remineralization. The ballast hypothesis is based on observations of a strong correlation between POC (particulate organic carbon) fluxes and the flux of biogenic minerals in deep sediment traps (Armstrong et al., 2002; François et al., 2002; Klaas and Archer, 2002). Ecosystem structure is also thought to play an important role (Guidi et al., 2009; Lam et al., 2011; Henson et al., 2012a, b; Wilson et al., 2012). According to this view, diatom-dominated phytoplankton communities in productive areas, such as high-latitude environments and upwelling regions, produce large, dense and relatively labile aggregates 
that are readily exported but decay rapidly at depth, resulting in a high export ratio but low transfer efficiency in these regions. Conversely, in lower-latitude oligotrophic environments, where diatoms are largely absent, primary production is low and mostly regenerated; consequentially, the small fraction of material that is eventually exported is likely to be refractory and undergo relatively little degradation at depth, resulting in low export ratio but high transfer efficiency. A "packaging effect" may also be at work (François et al., 2002). Carbonate-dominated regions tend to produce hydrodynamic, fast-sinking fecal pellets that reach greater depths (high transfer efficiency), while opal-dominated regions tend to produce slower sinking, loose aggregates that are rapidly remineralized in the mesopelagic (lower transfer efficiency). Understanding the processes that control the flux of particulate organic material to the deep ocean in order to quantify the strength and efficiency of the biological pump is essential to an accurate projection of the ocean's response to and feedback on anthropogenic perturbations.

Sparse in situ data from sediment traps have relatively high associated uncertainties and do not resolve the spatial variability in the vertical particle flux. This makes it difficult to understand the mechanisms driving the vertical particle flux and leads to large uncertainties in global and regional budgets. In this context, numerical models offer a powerful research tool. Models supplement observations by providing flux estimates in undersampled regions and at spatialtemporal coverage and resolution that are impractical or difficult to sample, thus allowing us to investigate phenomena poorly resolved by observational data. Models also provide the means to synthesize the available information into a practical and useful framework that can be used for quantitative analysis and evaluation, and as an heuristic tool that offers guidance and recommendations for future observations. In addition, comparison of model results with observations allows us to assess model skill and leads to improved mathematical representations of biogeochemical processes.

In this study, we use results from a three-dimensional, coupled physical-biogeochemical model in combination with in situ data from sediment traps to (1) investigate the processes controlling the export of particulate organic matter (POM) from the euphotic zone and its flux to depth, and (2) see how these processes interact to produce spatial and temporal variability in export ratios and transfer efficiencies. We also compare our model results with sediment trap data and other parameterizations of particulate organic carbon (POC) flux to depth to evaluate model skill and gain further insight into the causes of error and uncertainty in POC flux estimates.

\section{Methods}

\subsection{Model formulation}

The model used in this study is the Community Climate System Model-ocean Biogeochemical Elemental Cycle (CCSM-BEC) which consists of an upper-ocean ecological module (Moore et al., 2004) and a full-depth ocean biogeochemistry module (Doney et al., 2006) both embedded in a three-dimensional (3-D) global physical ocean general circulation model (Collins et al., 2006). The ecosystem module includes three phytoplankton functional groups (small picoplankton/nanoplankton, diatoms and diazotrophs), a general adaptive zooplankton class and multi-nutrient $(\mathrm{N}, \mathrm{P}, \mathrm{Si}$, $\mathrm{Fe}$ ) limitation on phytoplankton growth (Doney et al., 2009a, b). Calcification by coccolithophores is parameterized as a fraction of the picoplankton/nanoplankton production as a function of temperature and nutrients. The biogeochemistry module (Doney et al., 2006) is based on an expanded version of the Ocean Carbon Model Intercomparison Project (OCMIP) biotic model (Najjar et al., 2007) and includes full carbonate system thermodynamics, air-sea $\mathrm{CO}_{2}$ and $\mathrm{O}_{2}$ fluxes, nitrogen fixation and denitrification (Moore and Doney, 2007), and a dynamic iron cycle with atmospheric dust deposition, water-column scavenging and a continental sediment source. More detailed information on the ecological and biogeochemical components of the model is available in Moore et al. (2004), Doney et al. (2009a) and Doney et al. (2009b).

The treatment of sinking particulate organic material in CCSM-BEC is implicit and based on the ballast model of Armstrong et al. (2002). POC, particulate $\mathrm{CaCO}_{3}$ and opal are produced by phytoplankton and zooplankton mortality, and grazing by zooplankton on all three phytoplankton groups (Eqs. A1-A3 in Appendix A1). The vertical flux of POM is assumed to decay exponentially with depth with a remineralization length scale $(\lambda)$ that varies according to the mineral content of the organic matter. Sinking POM is assumed to have "free" and mineral-associated fractions. The mineral-associated portion is further divided into soft and "hard" fractions. The free fraction decays following the remineralization length scale for POC, while the mineralassociated fraction decays according to the corresponding soft mineral dissolution length scale. The hard mineralassociated fraction is assumed to be fast sinking and/or resistant to degradation (very long remineralization length scale) and thus to sink to the bottom of the ocean before remineralization. Ballast minerals include $\mathrm{CaCO}_{3}$ from coccolithophores, biogenic silica (opal) from diatoms and dust from atmospheric deposition. The remineralization of POC and opal are known to be strongly influenced by temperature, so the remineralization length scales for free POC and opal increase with decreasing water temperature following temperature response functions (Eqs. A15, A16 in Appendix A1). The remineralization length scale for free POC also increases 
in regions of low dissolved $\mathrm{O}_{2}\left(<4 \mathrm{mmolm}^{-3}\right)$ where organic matter is oxidized less efficiently through denitrification. The vertical particle flux model is, in essence, equivalent to a sum of exponentials in which the different terms, representing organic matter of different mineral composition under different environmental conditions, change in space and time. The vertical particle flux component of CCSM$\mathrm{BEC}$, including equations, parameter values and the routing of POC to the different subclasses, is described in more detail in Appendix A1.

The version of CCSM-BEC we use has a resolution of $3.6^{\circ}$ in longitude and $0.8-1.8^{\circ}$ in latitude, and 25 vertical levels (Yeager et al., 2006). The effects of mesoscale eddy transport and mixing are parameterized following Gent and McWilliams (1990). The Large et al. (1994) K-Profile Parameterization is implemented in the vertical to capture surface boundary-layer dynamics and interior diapycnal mixing. The ocean circulation model is forced with physical climate forcing from atmospheric reanalysis and satellite data products (Doney et al., 2007) and time-varying dust deposition (Mahowald et al., 2003). Analysis is performed on a 12month climatology computed from the last $20 \mathrm{yr}$ of a $840 \mathrm{yr}$ run with repeat annual cycle of physical forcing and dust deposition, and fixed pre-industrial atmospheric $\mathrm{CO}_{2}$ concentrations (280 ppmv). CCSM-BEC shows good skill in reproducing observed spatial distributions as well as seasonal and interannual variability patterns of sea surface temperature, mixed layer depth, surface chlorophyll and nutrients, and net primary production (Doney et al., 2007, 2009b).

\subsection{Model analysis}

We investigate the dynamics of vertical POC flux in CCSMBEC by fitting the model results to a relatively simple threeparameter exponential model of POC flux to depth and looking at the distribution and range of the fit parameter values, and their relationship to environmental and biogeochemical factors. The idea is to synthesize the complexity of CCSMBEC's particle flux model into a smaller, yet representative, set of parameters that can be more easily studied and understood. The exponential model of POC flux $(F)$ at depth $(z)$ is defined as

$F(z)=f \operatorname{NPP}\left(\alpha e^{-\frac{1}{\lambda}\left(z-z_{0}\right)}+(1-\alpha)\right)$,

where $f$ is the fraction of vertically integrated net primary production (NPP) that is exported (export ratio), $\alpha$ is the labile fraction of POC, $\lambda$ is the remineralization length scale, and $z_{0}$ is the export depth. The derivation of Eq. (1) is presented in Appendix A2.

To simplify analyses and computations, annual and seasonal (January-March, April-June, July-September, October-December) means of net primary production (NPP), POC production, and biomineral $\left(\mathrm{CaCO}_{3}\right.$ and opal), dust and POC vertical fluxes are computed from the 12-month climatology of model results. In this study, NPP is defined as the fixation of carbon by the phytoplankton groups through photosynthesis and POC production is defined as the production of dead particulate organic matter (detritus). Export depth (bottom of euphotic zone ) shows significant regional and seasonal variation (Najjar and Keeling, 1997; Buesseler and Boyd, 2009) and large differences (>100 m) between locations and/or seasons can significantly impact export estimates (Boyd and Newton, 1999). So export depth $\left(z_{0}\right)$ fields are computed from the annual and seasonal means as the depth where POC production is equal to $1 \%$ of maximum POC production in the water column. The parameters $\alpha, \lambda$ and $f$ are then estimated by fitting Eq. (1) through a nonlinear least squares technique to the annual and seasonal means of NPP and POC flux profiles at each CCSM-BEC grid point. Grid cells with water columns shallower than $900 \mathrm{~m}$ and/or with seasonal ice coverage greater than $10 \%$ are excluded from the analysis. The Arctic ocean region is also excluded from the analysis, due to the lack of observations to evaluate model skill in the region (see Sect. 2.3), and generally poor fits due to unrealistic model POC flux profiles, particularly under the ice in winter.

The range and distribution of $\alpha, \lambda$ and $f$ values represent variations in organic matter composition, transfer efficiency and export ratios, and reflect the flexibility and range of behavior of CCSM-BEC's particle flux model. Examination of the relationship between $\alpha, \lambda$ and $f$ values and environmental and biogeochemical factors gives us insight into the processes driving the export of POC from the euphotic zone and its flux to the deep ocean, and how these processes interact to produce spatial and temporal variability in export ratios and transfer efficiencies.

In addition to the exponential model parameters, we also examine direct CCSM-BEC estimates of POC flux, export ratios and transfer efficiencies. CCSM-BEC export ratio is computed as the annual POC flux at $z_{0}$ (export flux) divided by the annual vertically integrated NPP. Transfer efficiency is computed as the ratio of annual POC flux at $2000 \mathrm{~m}$ to the annual POC flux at $z_{0}$. We chose $2000 \mathrm{~m}$ as it is a commonly used reference depth for computing transfer efficiency (Henson et al., 2011, 2012b), and because particulate fluxes tend to not vary significantly below this depth (François et al., 2002; Honjo et al., 2008).

\subsection{Model evaluation}

We evaluate CCSM-BEC's skill by comparing model POC fluxes with in situ data from sediment traps. Here we use annual mean POC fluxes at 254 locations (Fig. 1), computed from a climatological year compiled by Lutz et al. (2007) using $25 \mathrm{yr}$ of observations from sediment traps. For the comparison, the CCSM-BEC mean annual POC flux is computed from the 12 month model climatology with POC flux values extracted at the locations and depths of the sediment traps. Model and observations are compared globally and for each individual region of the model domain (Fig. 1). 

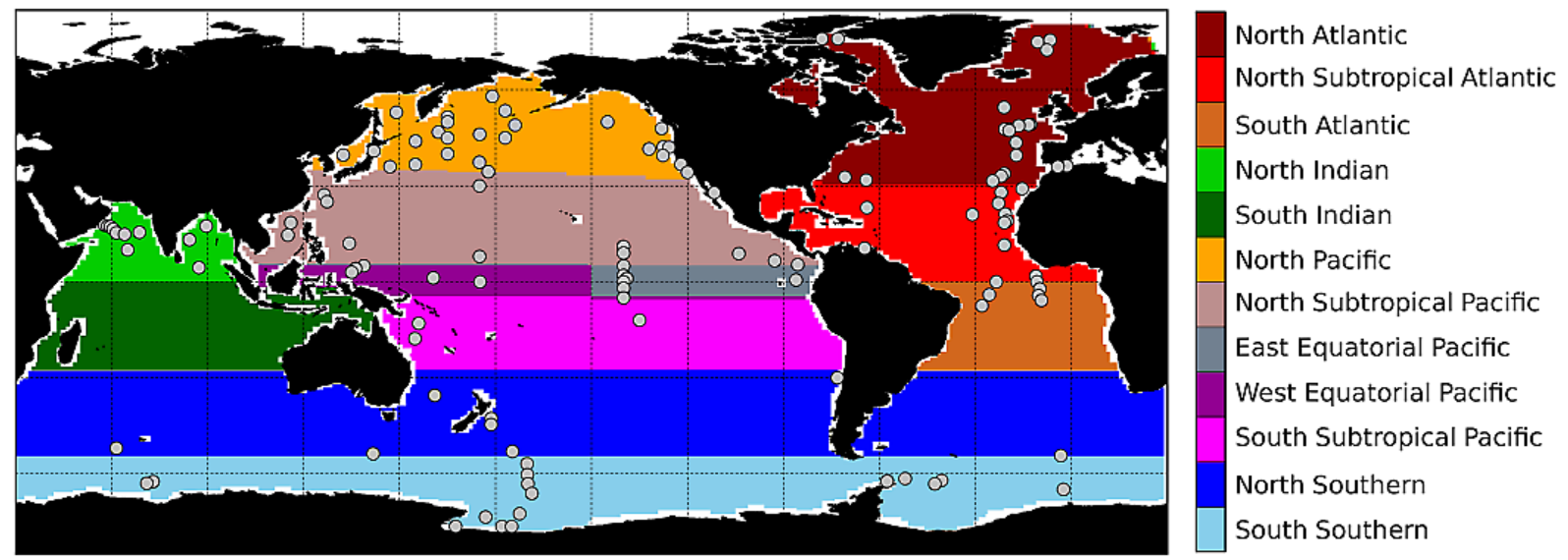

Fig. 1. CCSM-BEC model domain regions and location of sediment traps in the Lutz et al. (2007) data set.

We also compare CCSM-BEC's skill with that of other parameterizations of $\mathrm{POC}$ flux to depth to gain insight into the sources of bias, error and uncertainty in POC flux estimates. The empirical model of Lutz et al. (2007) and the exponential model (Eq. 1) presented in Sect. 2.2 are evaluated against the same sediment trap data from Lutz et al. (2007). The Lutz model estimates the annual mean POC flux at depth from annual mean NPP using an exponential relationship with parameters that vary spatially as functions of the seasonal amplitude in NPP (Lutz et al., 2007). The authors' assumption is that the fraction and biodegradability of exported production are mainly influenced by ecosystem structure, which is related to the seasonal amplitude in NPP. In stable environments, primary production is mostly regenerated so a smaller fraction of NPP is exported and the exported material is more refractory, while in seasonal environments, production exceeds consumption and recycling, so a larger fraction of NPP is exported in a more labile state. POC flux estimates are computed at the locations and depths of the sediment traps using the Lutz model and CCSM-BEC-derived and satellitederived NPP extracted at the sediment trap locations. Satellite NPP is computed from a $1 \times 1^{\circ}$ monthly climatology of surface chlorophyll from SeaWiFS (Sea-viewing Wide Field-of-view Sensor) using the VGPM (Vertically Generalized Production Model) model of Behrenfeld and Falkowski (1997). To investigate the effect of factors associated with the seasonal amplitude in NPP on POC flux estimates, we compute POC flux at the locations and depths of the sediment traps using a "null" version of the Lutz model, in which the parameters are set to their spatial means and held constant for all locations.

POC flux estimates are also obtained using the exponential model (Eq. 1), fitted to the sediment trap measurements and NPP data, to compute POC flux at the locations and depths of the sediment traps. We fit Eq. (1) to all 254 POC flux observations combined, using annual mean NPP values from both satellite and CCSM-BEC extracted at the sediment trap loca- tions. This results in two sets of global parameters $\alpha, \lambda$ and $f$, one for each NPP data set (satellite and CCSM-BEC), that are used to compute POC flux at the sediment trap locations. To examine the effect of regional variations in organic matter composition, remineralization length scale and export ratios on POC flux estimates, we fit Eq. (1) to sediment trap and NPP data grouped by model domain region (Fig. 1). This is also done using both satellite and CCSMBEC NPP. The POC flux is then computed at the sediment trap locations using regionally varying $\alpha, \lambda$ and $f$ values, and their corresponding NPP data set (satellite and CCSM$\mathrm{BEC})$. In the regions where the fit is poor or where there are no observations, $\alpha, \lambda$ and $f$ are set to the global values computed in the previous step. The export depth $\left(z_{0}\right)$ is set to the CCSM-BEC global average (110.4 m, Fig. 4b) in all exponential model fits. In summary, we evaluate eight different parameterizations of POC flux to depth against the sediment trap data. Namely, the CCSM-BEC model, the Lutz et al. (2007) model with satellite and CCSM-BEC NPP, the Lutz et al. (2007) null model with satellite NPP, and the exponential model (Eq. 1) with satellite and CCSM-BEC NPP and with constant and regionally varying parameters.

In this study, we use the simple exponential model (Eq. 1) in two different ways. First we use it to "summarize" the complexity of the CCSM-BEC particle flux model in a small set of parameters $(\alpha, \lambda$ and $f)$ that are then used to describe and analyze the behavior of the CCSM-BEC model. The spatial and seasonal distributions of these parameters and their errors, and their relationship with environmental and biogeochemical factors, give us insight into the processes and mechanisms controlling the export and transfer efficiency in the CCSM-BEC model (Section 3.3). We also use the exponential model, fitted to sediment trap measurements, in the skill evaluation of different models/parameterizations against observations. Comparison of models of varying complexity against observations gives us insight into the sources of bias and uncertainty in the different parameterizations, and tells 
us whether observations provide enough contrast and resolution to adequately evaluate models (Section 3.1 and Section 4).

\section{Results}

\subsection{Comparison with observations}

Overall, CCSM-BEC does a reasonably good job estimating the observed annual mean POC fluxes at the locations and depths of the sediment traps in the Lutz data set. A type II linear regression of $\log _{10}$-transformed POC flux estimates from CCSM-BEC against $\log _{10}$-transformed observations results in a correlation coefficient of 0.65 and a slope of 0.91 (Fig. 2a). However, the agreement between model and observations can vary significantly by region. CCSM-BEC estimates are consistent with observations in most regions (Fig. 2b, g-1), with correlations ranging from 0.81 (northern subtropical Atlantic) to 0.56 (North Pacific). In the northern subtropical Pacific (Fig. 2g) and northern subtropical Atlantic (Fig. 2k), CCSM-BEC tends to underestimate the POC flux at the shallower traps, and in the North Pacific (Fig. 2h) CCSM-BEC consistently underestimates the sediment trap fluxes at all depths. In the southern subtropical Pacific and western equatorial Pacific (Fig. 2d, e), CCSM-BEC and observations are uncorrelated $(r=-0.08)$ and negatively correlated $(r=-0.25)$, respectively. This is due to the combination of a low number of observations in these regions and errors and uncertainties in the model and sediment trap estimates. Model and observational errors, which tend to cancel each other out in large samples, have a larger impact on correlations and regression slopes when sample size is small. CCSM-BEC also significantly underestimates the flux at four of the nine sediment traps in the western equatorial Pacific, resulting in a negative correlation with observations. In the eastern equatorial Pacific (Fig. 2f), observations vary within a narrow range $\left(0.2-0.5 \mathrm{mmol} \mathrm{m}^{-2} \mathrm{~d}^{-1}\right)$, and thus uncertainties in the model and sediment trap estimates have a larger relative impact, resulting in a large scatter around the regression line and low correlation $(r=0.23)$. In the northern Southern Ocean, the trend is correct $(b \approx 1)$ but the overestimation and underestimation of the fluxes at shallow and deep traps, respectively, results in a wide scatter and low correlation $(r=0.30)$.

Figure 3 shows the estimated annual mean POC fluxes at sediment trap locations and depths from eight different parameterizations of POC flux to depth (including CCSMBEC) plotted against observations from the Lutz data set. With some variation, all parameterizations show reasonably good skill in reproducing the annual mean POC fluxes estimated from sediment traps. Type II regression slopes from the $\log _{10}$-transformed fluxes vary between 0.71 and 0.97 , and correlation coefficients range from 0.5 to 0.72 . In the CCSM-BEC and Lutz models, different regional errors and biases compensate for each other, resulting in similar overall skill for both models $(r \approx 0.65, m>0.9)$. The Lutz model overestimates the POC flux in the North Atlantic and underestimates it in the eastern equatorial Pacific and in many locations in the northern Indian Ocean, while CCSM-BEC underestimates the POC flux in the northern subtropical Atlantic and North Pacific and overestimates it in the eastern equatorial Pacific and several locations in the northern and southern Southern Ocean. The negligible difference in skill between the Lutz and the Lutz null models (Fig. 3b, c) suggests that the seasonal amplitude in NPP has little effect on model skill or that it is not a good proxy for differences in ecosystem structure. Another possible explanation is that the magnitude of NPP (annual mean) already contains information on ecosystem structure. Diatoms tend to be dominant in productive (high annual NPP) regions, while nanoplankton/picoplankton are dominant in oligotrophic areas (low annual NPP). Given the correlation between NPP and phytoplankton community structure, the added effect of variations in the seasonal amplitude in NPP may not be significant compared to the relatively large uncertainties in sediment trap estimates. The Lutz model shows lower skill $(r=0.5, b<0.9)$ when using NPP from CCSM-BEC. This is in part expected as the equations used to compute the parameters in Lutz's exponential relation were obtained from fits to the seasonal variation index (SVI = temporal coefficient of variation of 12 month climatology, Lutz et al. (2007)) of SeaWiFS NPP. Therefore, errors and biases in CCSM-BEC NPP can have an effect. CCSM-BEC significantly underestimates NPP in parts of the North Pacific and in the northern subtropical Atlantic along the upwelling region off the west coast of Africa (Doney et al., 2009b), where a number of the sediment traps are located (Fig. 1). As a result, the Lutz model with CCSMBEC NPP underestimates the POC flux in a large number of locations in these regions. The SVI for CCSM-BEC NPP is also significantly higher than that for SeaWiFS NPP at many trap locations in the North Atlantic and northern and southern Southern Ocean. This leads to significantly higher export ratios and a decrease in the remineralization length scale in the Lutz model, and a net increase in the POC flux to depth at these locations compared to estimates using SeaWiFS NPP. The underestimation of POC fluxes at sites in the North Pacific and northern subtropical Atlantic, and the overestimation of POC fluxes at locations in the North Atlantic and Southern Ocean, result in a wider scatter and lower correlation for the Lutz model using CCSM-BEC NPP (Fig. 3d).

As expected, the exponential model (Eq. 1) with regionally varying parameter values $(\alpha, \lambda, f)$ (Fig. $3 \mathrm{~g}, \mathrm{~h}$ ) shows better skill (higher correlation, slope closer to 1) than the exponential model with spatially constant parameters (Fig. 3e, f). However, due to its simpler formulation, the exponential model does not provide the flexibility necessary to reproduce the observed variation in POC flux profiles, and all four parameterizations of the exponential model (global, regional, satellite, and CCSM-BEC NPP) tend to 
underestimate shallow fluxes and overestimate deep fluxes (Fig. 3e-h), when compared to CCSM-BEC or the Lutz model (Fig. 3a-d). As in the case of the Lutz model, errors and biases in CCSM-BEC NPP lead to a wider scatter and lower correlations between model estimates and observations in both the global and regional exponential models (Fig. 3eh).

The magnitude of export ratios $(f)$ in CCSM-BEC and their relationship with sea surface temperature (SST) are consistent with those reported in Henson et al. (2011) (Fig. 8d). Export ratios are inversely correlated with SST $(r=-0.6)$, ranging from $0.07-0.3$ in temperate and subpolar regions to $0.03-0.2$ in warm subtropical and equatorial waters. The wide scatter in the northern and southern Southern Ocean, subtropical Pacific and Atlantic (northern and southern) and Indian Ocean (northern and southern) results from the fact that export ratios in CCSM-BEC are mainly a function of the relative abundance of diatoms, which varies significantly in these regions (Fig. 8h). The subtropical Pacific and Atlantic and the Indian Ocean include productive upwelling areas where diatoms dominate and oligotrophic areas where diatoms are virtually absent. The Henson et al. (2011) export ratio estimates, however, include values higher than 0.35 in the Southern Ocean and lower than 0.03 in the subtropics, and the export ratio estimates from CCSM-BEC are generally higher in the subtropics and lower in higher latitudes than those from the Henson et al. (2011) exponential relationship (Fig. 8d). Except for regions with SST $>25^{\circ} \mathrm{C}, \mathrm{CCSM}-$ BEC estimates of export ratios are significantly lower than those from the linear $f$ vs. SST relationship of Laws et al. (2000).

\subsection{CCSM-BEC global patterns}

Annual mean export depth $\left(z_{0}\right)$ in CCSM-BEC is generally shallower $(<100 \mathrm{~m})$ in productive areas, such as coastal and equatorial upwelling and high-latitude regions, where both the euphotic zone and mixed layer are relatively shallow during the productive months, and deeper $(>120 \mathrm{~m})$ in the oligotrophic gyres, where the euphotic zone is deep $(>100 \mathrm{~m})$, and parts of the North Atlantic with very deep winter mixed layers (Fig. 4a, b). Strong vertical mixing transports plankton deeper in the water column so grazing, mortality and POC production can occur below the euphotic zone, independent of light and NPP. Export depth is also higher (> $120 \mathrm{~m}$ ) in the Gulf Stream and Kuroshio frontal zones, and along the subpolar front in the Indian and Pacific sectors of the northern Southern Ocean, due to deep mixing associated with strong air-sea cooling and evaporation and mode water formation (see for example Marshall et al., 2009). Export flux (POC flux at $z_{0}$ ) closely resembles NPP (Fig. $4 \mathrm{~b}, \mathrm{c}$ ) and the two fields are well correlated $(r=0.82)$. Particle export is high $\left(>20 \mathrm{~g} \mathrm{C} \mathrm{m}^{-2} \mathrm{yr}^{-1}\right)$ in upwelling and high-latitude regions, and very low $\left(<2 \mathrm{gC} \mathrm{m}^{-2} \mathrm{yr}^{-1}\right)$ in the center of subtropical oligotrophic gyres (Fig. 4c). As expected, particle ex- port tends to be higher where the export depth is shallow and vice versa, with exception of the Gulf Stream and Kuroshio frontal zones, where export fluxes are relatively high and the export depth is deeper than $120 \mathrm{~m}$ (Fig. 4a, c). The highest export fluxes ( $>40 \mathrm{~g} \mathrm{Cm}^{-2} \mathrm{yr}^{-1}$ ) are observed in the equatorial and coastal upwelling regions off the west coast of Africa and South America, the Arabian Sea, the subpolar frontal zones south of Australia and New Zealand, and off the southeast coast of South America (Fig. 4c). The globally integrated total POC export across spatially varying export depth $\left(z_{0}\right)$ is $6.04 \mathrm{Pg} \mathrm{Cyr}^{-1}$. The flux of POC at $2000 \mathrm{~m}$ shows similar geographical patterns to the particle export (Fig. 4c, d), with values ranging from less than $0.2 \mathrm{~g} \mathrm{Cm}^{-2} \mathrm{yr}^{-1}$ in the oligotrophic gyres to greater than $2 \mathrm{~g} \mathrm{Cm}^{-2} \mathrm{yr}^{-1}$ in the equatorial Pacific, Arabian Sea and the subpolar frontal region off the southeast coast of South America (Fig. 4d). The globally integrated total POC flux at $2000 \mathrm{~m}$ is $0.21 \mathrm{PgC} \mathrm{yr}^{-1}$.

Export ratio is high $(>20 \%)$ in upwelling and highlatitude regions, where production is high and export depths are shallow; it is low $(<5 \%)$ in the center of oligotrophic gyres, where NPP is very low and export depths are deep (Fig. 4a, b, e). Areas of moderate production and deep export depths in the northern Southern Ocean and parts of the North Atlantic have export ratios of the order of $10 \%$ (Fig. 4e). The global area-weighted mean export ratio is $12.9 \%$. Transfer efficiency and export ratio have generally opposing spatial distributions, except for the upwelling region in the equatorial Pacific and west coast of South America, where both are higher than the global mean. Transfer efficiency is high $(>7 \%)$ in the center of oligotrophic gyres, reaching up to $40 \%$ in center of the North Atlantic gyre, and low $(<5 \%)$ in productive high-latitude regions and over most of the subtropical western Pacific (Fig. 4e, f). The global area-weighted mean transfer efficiency is $5.5 \%$.

\subsection{Exponential model}

The least-squares fit of the exponential model (Eq. 1) to CCSM-BEC annual and seasonal means of vertical POC flux and NPP is very good. Linear regressions of "predicted" (exponential model) against "observed" (CCSM-BEC) POC flux at export depth $\left(z_{0}\right)$, and at 500, 1000 and $2000 \mathrm{~m}$ produce slopes and correlation coefficients very close to 1 (Table 1). We are thus confident that the exponential model accurately represents the range of behavior of CCSM-BEC's vertical particle flux model.

The spatial distribution of the parameters $\alpha, \lambda$ and $f$ and their standard errors, obtained from fitting Eq. (1) to CCSMBEC annual mean POC flux profiles and NPP, is shown in Fig. 5. Labile fraction of POC $(\alpha)$ is above $90 \%$ over most of the ocean, except in high dust deposition regions (Arabian Sea and the North Atlantic subtropical gyre), where it reaches values below $40 \%$ (Fig. 5a). Labile fraction and transfer efficiency have spatially opposing patterns (Figs. $4 \mathrm{f}$ and 5a). Regions with lower labile fraction $(80 \%<\alpha<95 \%)$ in the 

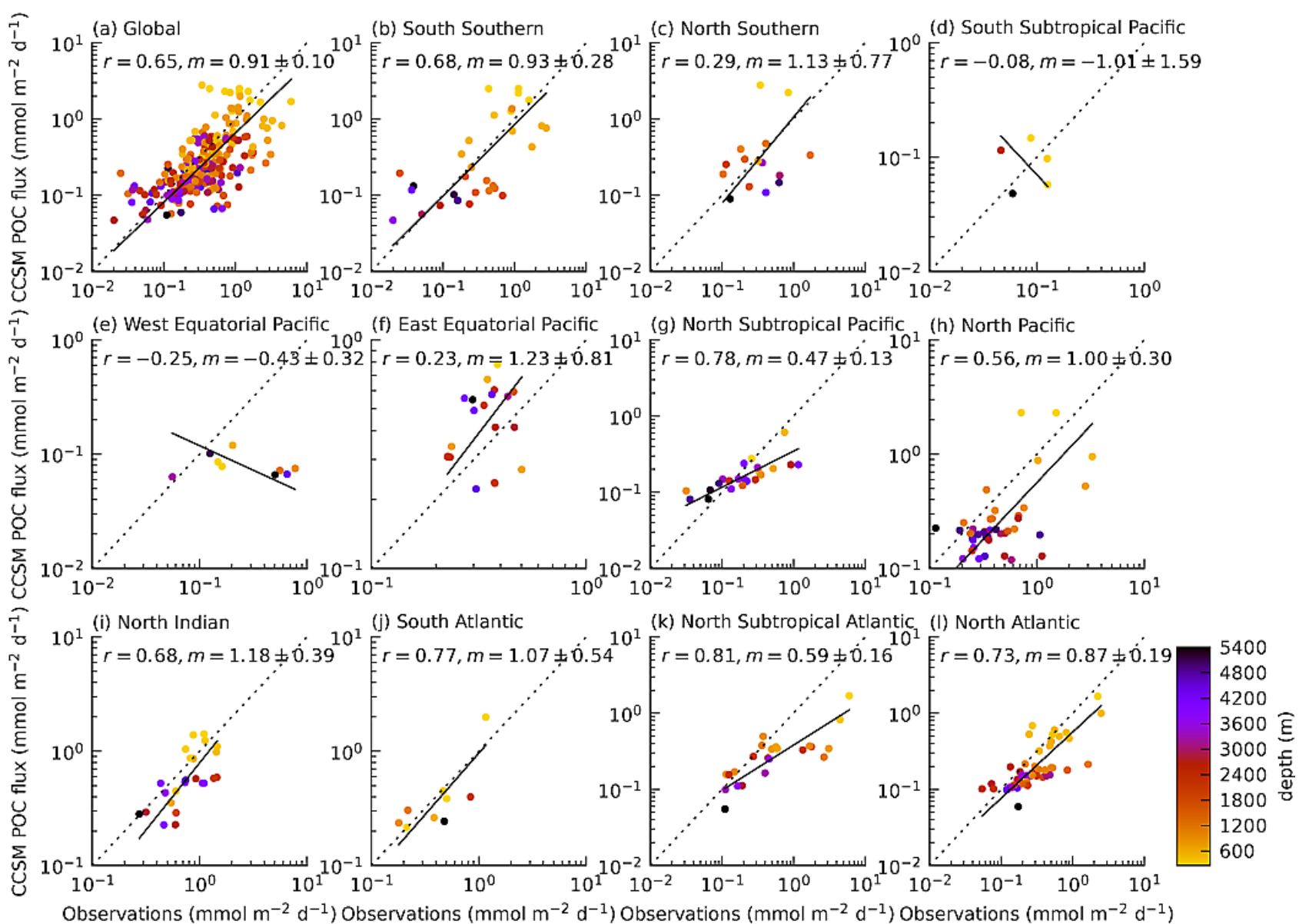

Fig. 2. Annual mean POC flux from CCSM-BEC model at sediment trap locations and depths plotted against observations from the Lutz data set for the whole globe (all points combined) and each domain region (Fig. 1). Sediment trap data is absent in the southern Indian Ocean, so that region is not shown. Solid black lines show type II linear regression and dotted black lines show the $1: 1$ slope. The correlation coefficient $(r)$ and regression slope $(m)$ for the $\log _{10}$-transformed data are shown in each panel. Color scale indicates depth of sediment traps.

Table 1. Parameters from type II linear regressions of POC flux estimates from exponential model (Eq. 1) against POC flux from CCSM-BEC at different depths. The regression slopes are shown with their $95 \%$ confidence interval. The linear regressions were computed using annual and seasonal means of POC flux from CCSM-BEC and their corresponding exponential model fit (annual and seasonal, see Sect. 2.2).

\begin{tabular}{lcccc}
\hline \multirow{2}{*}{ depth } & \multicolumn{2}{c}{ annual } & \multicolumn{2}{c}{ seasonal } \\
& slope & correlation & slope & correlation \\
\hline$z_{0}$ & $0.983 \pm 0.002$ & 0.998 & $1.017 \pm 0.001$ & 0.998 \\
$500 \mathrm{~m}$ & $0.952 \pm 0.004$ & 0.989 & $0.985 \pm 0.002$ & 0.993 \\
$1000 \mathrm{~m}$ & $1.141 \pm 0.007$ & 0.971 & $1.105 \pm 0.003$ & 0.981 \\
$2000 \mathrm{~m}$ & $1.044 \pm 0.003$ & 0.995 & $1.039 \pm 0.001$ & 0.996 \\
\hline
\end{tabular}

subtropical parts of the South Atlantic, North and South Pacific, east equatorial Pacific, and along the subpolar fronts in the South Pacific and southern Indian Ocean correspond to areas of higher transfer efficiency (Fig. 4f), and regions of higher labile fraction $(\alpha>95 \%)$ in the North Atlantic and Pacific and just south of the equatorial Pacific have low transfer efficiency. The POC remineralization length scale $(\lambda)$ generally increases with latitude, most likely due to temperature effects (see Sect. 2.1). $\lambda$ ranges from $\approx 150 \mathrm{~m}$ in the tropics and subtropics to greater than $200 \mathrm{~m}$ at high-latitudes regions (Fig. $5 \mathrm{c}$ ). The highest values $(>250 \mathrm{~m})$, however, occur in the upwelling region off the west coast of the Americas, in the northern Indian Ocean and in a small region in the North Atlantic subtropical gyre. The lower labile fraction $(<50 \%)$ and higher remineralization length scale $(>250 \mathrm{~m})$ in the northern subtropical Atlantic are indicative of a higher proportion of POC reaching the deep ocean, and thus high transfer efficiency as shown in Fig. 4f. The distribution of export ratio $(f)$ in the exponential model (Fig. 5e) is virtually identical to that from CCSM-BEC (Fig. 4e), highlighting the good fit of the exponential model. 

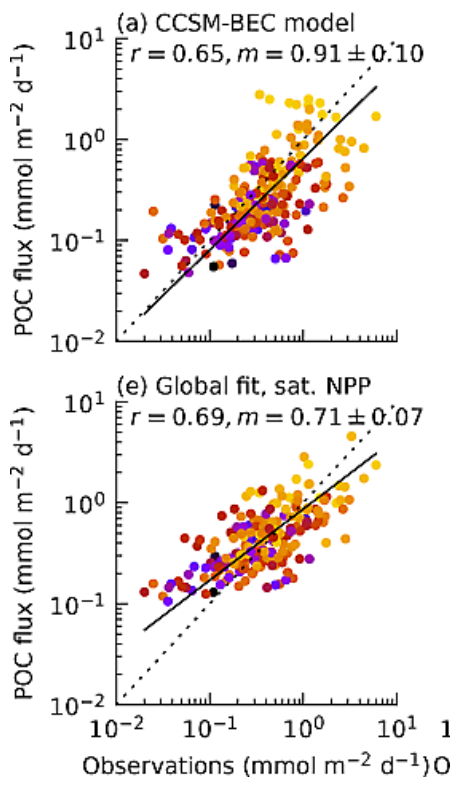

(b) Lutz model, sat. NPP

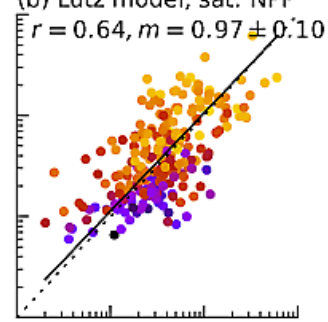

(f) Global fit, CCSM-BEC NPP

$r=0.56, m=0.72 \pm 0.08$

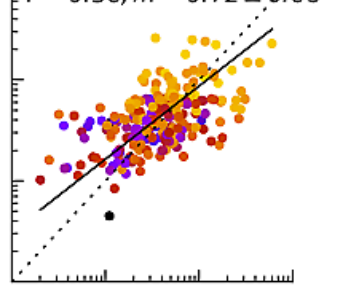

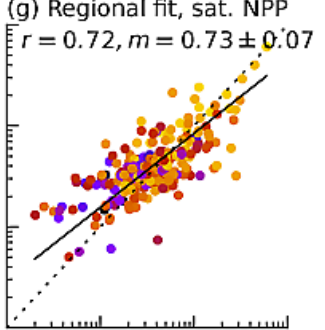

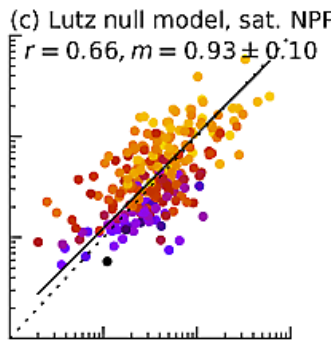

(d) Lutz model, CCSM-BEC NPP

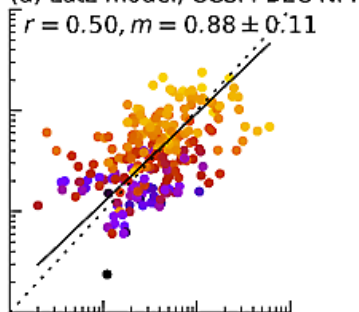

(h) Regional fit, CCSM-BEC NPP

$r=0.61, m=0.82 \pm 0.09$

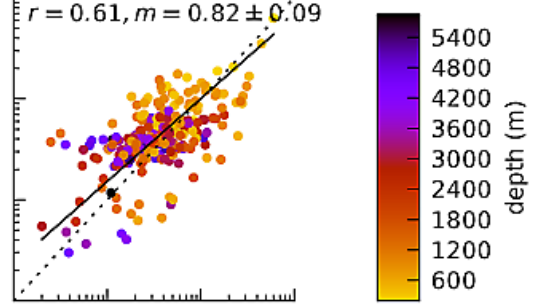

Fig. 3. POC flux estimates at sediment trap locations plotted against observations from the Lutz data set: (a) CCSM-BEC model, (b) Lutz model using satellite NPP, (c) Lutz null model using satellite NPP, (d) Lutz model using CCSM-BEC NPP; (e) and (f) show estimates from fit of exponential curve (Eq. 1) to Lutz data set (all data points combined) using NPP from satellite and CCSM-BEC, respectively; (g) and (h) show estimates from fit of exponential curve (Eq. 1) to Lutz data set for each region of the model domain (Fig. 1) using NPP from satellite and CCSM-BEC, respectively. In (g) and (h), the regions with no observations or poor fit use parameter values from the global fit (e and $\mathbf{f})$. Solid black lines show the type II linear regression of the $\log _{10}$-transformed data. The correlation coefficient $(r)$ and regression slope $(m)$ are shown in each panel. Color scale indicates depth of sediment traps.

The seasonal cycles of $\alpha, \lambda$ and $f$ for each of the model domain regions (Fig. 1) are shown in Fig. 6a-c. Labile fraction of POC $(\alpha)$ remains relatively constant and above $90 \%$ in most regions (Fig. 6a). In the northern subtropical Atlantic, $\alpha$ is significantly lower, ranging from $85 \%$ in winter to less than $75 \%$ in the summer months. In the northern Indian Ocean and northern and southern Southern Ocean, $\alpha$ also reaches a minimum in summer and winter, respectively. In the North Atlantic, $\alpha$ is close to $95 \%$ for most of the year but drops below $90 \%$ in winter. The seasonal decrease in the POC labile fraction in these four regions is directly related to the increase in the fraction of dust in the particulate sinking detritus (Fig. 6g). In the northern subtropical Atlantic, North Atlantic, and southern Southern oceans, atmospheric dust deposition is relatively constant in time, so the minima in $\alpha$ occur when NPP is at its lowest value (winter in the southern Southern Ocean and North Atlantic and summer in the northern subtropical Atlantic, Fig. 6f). In the northern Indian Ocean, the decline in POC labile fraction in summer is smaller, and is associated with a marked increase in atmospheric dust deposition (not shown).

The decreases in POC labile fraction in the North Atlantic in winter and the northern subtropical Atlantic in the summer are accompanied by a significant increase in the POC remineralization length scale $(\lambda)$, denoting seasonal variations in transfer efficiency in these regions (Fig. 6a, b). Low labile fraction and long remineralization length scale in these regions are the result of low productivity and elevated dust deposition (Figs. $4 \mathrm{~b}$ and 5c). The small increase in $\lambda$ in the northern Southern Ocean in winter can be attributed to lower temperatures and higher fraction of $\mathrm{CaCO}_{3}$ in sinking particulate material (Fig. 6d, i). The increase in the ratio of $\mathrm{CaCO}_{3}$ to POC flux in the northern Southern Ocean in winter is due to a decrease in the export of $\mathrm{POC}$ relative to $\mathrm{CaCO}_{3}$, rather than an increase in $\mathrm{CaCO}_{3}$ flux. On a regional scale, export ratio $(f)$ is generally proportional to the ratio of primary production by diatoms to total primary production (Fig. 6c, e). Regions with high $\mathrm{NPP}_{\text {diat }} / \mathrm{NPP}_{\text {tot }}$ have high $f$ and vice versa. This broad spatial pattern is modulated by seasonal variations at high-latitude regions (southern Southern Ocean, northern Southern Ocean, North Atlantic and North Pacific) where export ratios follow the annual cycle in NPP (Fig. 6c). In the southern Southern Ocean, NPP and, consequently, export ratios, are very low in austral winter due to severe light limitation despite the higher $\mathrm{NPP}_{\text {diat }} / \mathrm{NPP}_{\text {tot }}$ (Fig. 6e) caused by a decrease in the relative abundance of picophytoplankton due to picophytoplankton higher light requirements (lower maximum $\mathrm{Chl}: \mathrm{N}$ ratio).

The magnitude of the standard error of the estimates of $\alpha$, $\lambda$, and $f$ is inversely proportional to the goodness of fit of the exponential model. Therefore, regions characterized by high standard errors, such as the northern subtropical Atlantic, the northern Indian Ocean and the west coast of the Americas, denote areas where the fit of the exponential is not as good 

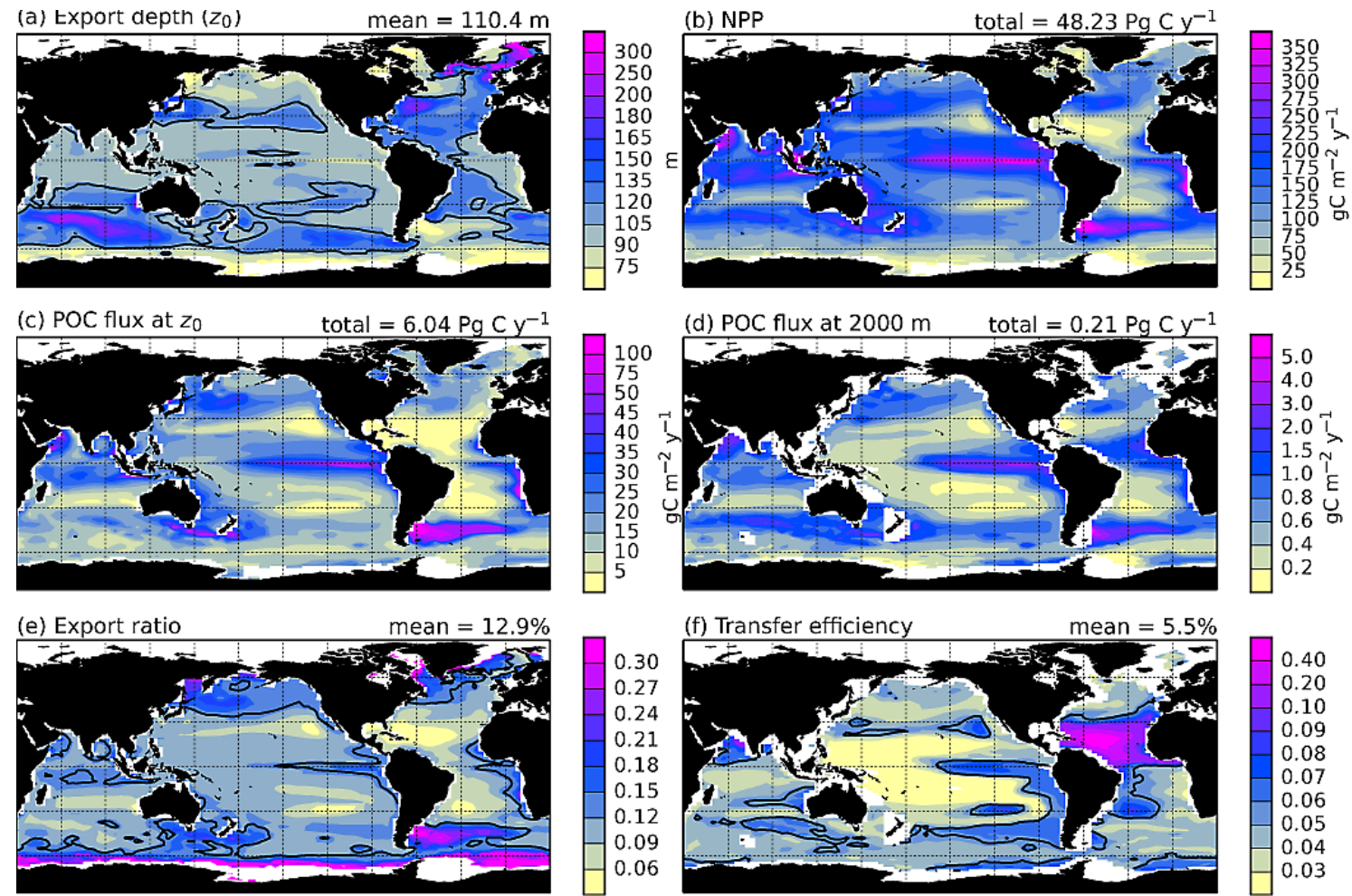

Fig. 4. CCSM-BEC annual mean export depth (a), annual net primary production (NPP) (b), POC flux at export depth (c) and $2000 \mathrm{~m}$ (d), export ratio (e) and transfer efficiency (f). Export ratio (e) is defined as POC flux at export depth (c) divided by annual NPP (b). Transfer efficiency (f) is defined as POC flux at $2000 \mathrm{~m}$ (d) divided by POC flux at export depth (c). Global integrals (NPP, POC flux at export depth and $2000 \mathrm{~m}$ ) and means (export depth, export ratio and transfer efficiency) are shown on the top right corner of the each panel. The solid black lines in (a), (e) and (f) denote the contour for the global mean value.

(Fig. 5b, d, f). Globally, the coefficients of variation for all three parameters are quite low $(<5 \%)$ and given their confidence intervals at each grid point, the spatial variations in $\alpha, \lambda$, and $f$ shown in Fig. 5a, c, e are statistically significant. Nevertheless, analysis of the causes of the poorer fits can inform us about the factors or processes that control the POC flux in those regions and contribute to the spatial variation in $\alpha, \lambda$ and $f$. Figure $7 \mathrm{a}-\mathrm{c}$ shows individual POC flux profiles from CCSM-BEC and the fitted exponential model at the locations marked in Fig. 5. The profiles are located in regions of high standard errors for all three parameters and the misfits between the exponential model and CCSM-BEC are noticeable. In the northern Subtropical Atlantic (Fig. 7a), the low (mostly regenerated) NPP (Fig. 4b) and the high proportion of dust $(>70 \%)$ in the particulate sinking material (Fig. 7e) result in a combination of low export $(f<5 \%)$ and slow decay $(\alpha<40 \%, \lambda>250 \mathrm{~m})$ that the exponential model is unable to fit well. On the west coast of South America and Africa and in the Arabian Sea region (Fig. 7b-d), the misfits are caused by the lengthening of the POC remineralization length scale between 300 and $700 \mathrm{~m}$, due to low dissolved $\mathrm{O}_{2}$ concentrations $\left(\mathrm{O}_{2}<4 \mathrm{mmolm}^{-3}\right.$, Fig. $\left.7 \mathrm{f}\right)$. In CCSMBEC, the remineralization length scale for POC is doubled in regions where organic matter is oxidized through denitrification (see Table 7 in Appendix A1). The higher $\lambda$ (> $250 \mathrm{~m}$ ) regions on the west coast of Africa and the Americas and in the northern Indian Ocean (Fig. 5c) are thus directly associated with oxygen minimum zones (OMZs) in CCSM-BEC.

The wide range of variation in $\alpha, \lambda$ and $f$ (Figs. 5 and 8) highlights the flexibility of CCSM-BEC's vertical particle flux model and its ability to simulate widely different POC flux regimes. Globally, export ratios $(f)$ vary by an order of magnitude (3-35\%) and POC remineralization length scales $(\lambda)$ vary by a factor of two $(150-330 \mathrm{~m})$. The largest variations in labile fraction $(40 \%<\alpha<95 \%)$ are confined to the northern subtropical Atlantic and northern Indian Ocean regions and are driven by an increase in the dust: $P O C$ ratio of exported material (Fig. 8j), caused by elevated atmospheric dust deposition. In parts of the North Atlantic and the Indian sector of the northern Southern Ocean, labile fraction also drops below $90 \%$ as a result of an increase in the $\mathrm{CaCO}_{3}: \mathrm{POC}$ ratio of sinking material (Figs. 5a and $8 \mathrm{q}$ ). In the remaining regions, there is still significant variability in the lability of sinking POC, with the refractory fraction $(1-\alpha)$ varying by a factor of four $(0.02-0.08$, Fig. 8 a). The variation in remineralization length scale $(\lambda)$ 

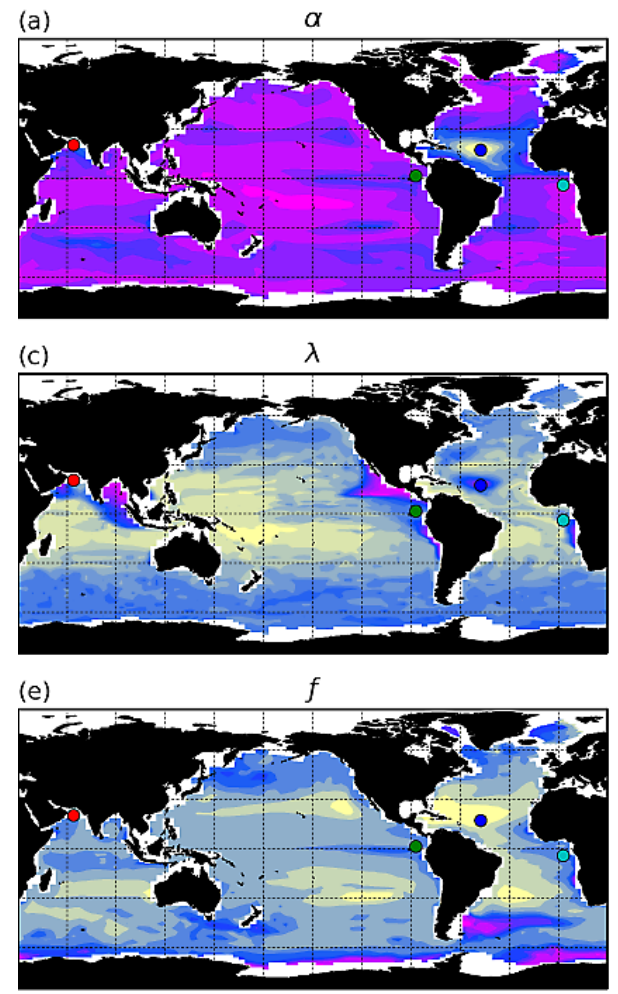
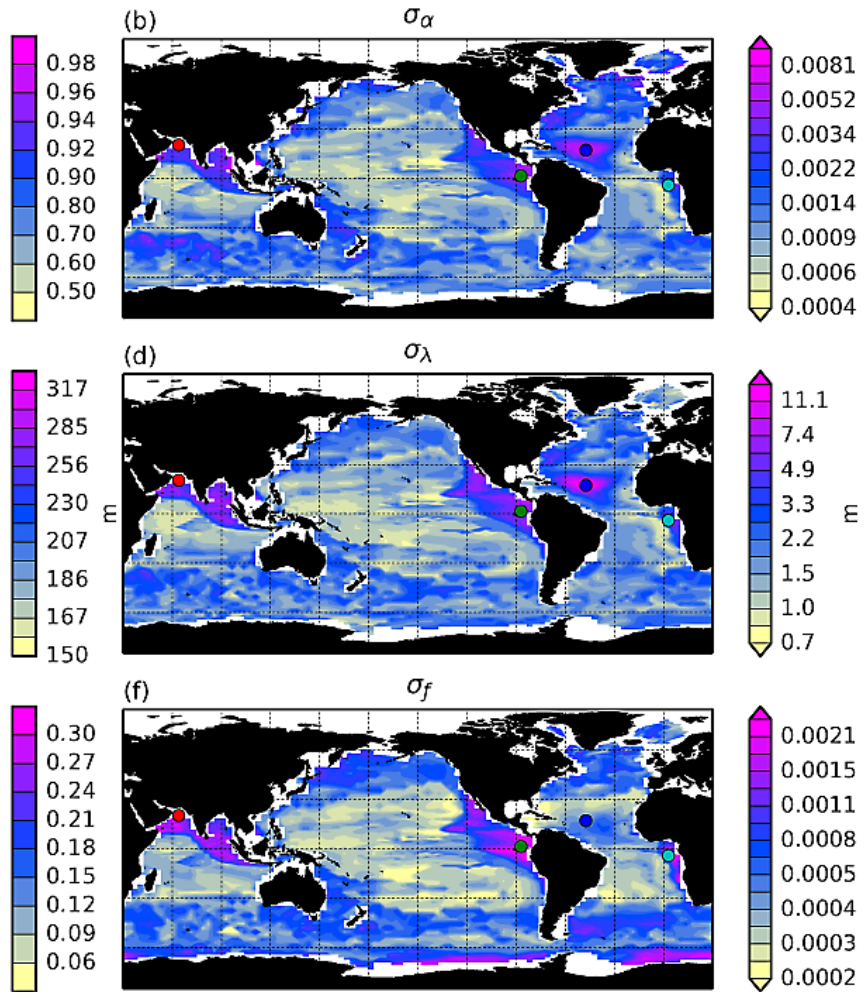

Fig. 5. Distribution of POC labile fraction $(\alpha)$, remineralization length scale $(\lambda)$ and export ratio $(f)(\mathbf{a}, \mathbf{c}, \mathbf{e})$ and their standard errors $(\mathbf{b}, \mathbf{d}$, f) obtained from fitting Eq. (1) to CCSM-BEC annual mean POC flux profiles and NPP at each model grid point. The colored circles mark the location of the vertical profiles shown in Fig. 7.

is largely controlled by water column temperature, ranging from $\approx 200 \mathrm{~m}$ in colder high-latitude regions to a minimum of $\approx 150 \mathrm{~m}$ in the warmest areas of the northern subtropical Pacific and western equatorial Pacific (Fig. 8b). This is expected as the temperature dependence of the POC remineralization length scale is built into the CCSM-BEC model and there is significant latitudinal variation in temperature in the mesopelagic in CCSM, with temperatures at $590 \mathrm{~m}$ varying from below $-2{ }^{\circ} \mathrm{C}$ in polar regions to $9-14{ }^{\circ} \mathrm{C}$ in the subtropical gyres (not shown). The large $\lambda$ values $(>250 \mathrm{~m}$ ) at high SSTs (Fig. 8b) are associated with the OMZ regions along the west coast of Africa and the Americas and the northern Indian Ocean. In the northern subtropical Atlantic, $\lambda$ increases with the dust content in the exported material (Fig. 8k) and the highest $\lambda$ values $(>200 \mathrm{~m}$ ) are associated with areas of low productivity and elevated dust deposition (Figs. 4b and 5c). The combination of low labile fraction $(\alpha<50 \%)$ and high remineralization length scale $(\lambda>200 \mathrm{~m})$ in the northern subtropical Atlantic, caused by high dust : POC ratios in sinking detritus, produces the highest transfer efficiencies in CCSM-BEC (Fig. 4f).

In CCSM-BEC, variability in export ratio is primarily driven by ecosystem structure (diatom relative abundance) and water column temperature (Fig. 8d, h, Table 2). This is expected as CCSM-BEC is parameterized so that a larger fraction of zooplankton grazing is routed to POC when zooplankton feed on diatoms, and the POC remineralization length scale decreases with increasing temperature (see Appendix A1). Multivariate linear regression analysis (Table 2) shows that, despite the apparent correlation between export ratios and opal and dust export (Fig. 8p, 1), the opal and dust content of exported material does not affect the export ratio in CCSM-BEC (negligible differences in $r^{2}$, Table 2). The negative regression coefficients between $\mathrm{CaCO}_{3}$ content of exported material and export ratio evidently reflect the dominance of diatoms in regions of high export ratio, and not a "negative" ballast effect by $\mathrm{CaCO}_{3}$ (Table 2). Removal of $\mathrm{CaCO}_{3}$ content of exported material from the regression results in a relatively small decrease in the explained variance (Table 2). Comparison of Fig. 8p and Table 2 also shows that the apparent correlation between export ratio and the opal : POC ratio in the export flux $(r=0.56$, Fig. $8 p)$ is the result of diatom dominance in regions of high export ratios, and not evidence of a ballasting effect by opal.

\subsection{Deep fluxes and transfer efficiency in CCSM-BEC}

To look at the effects of ecosystem structure and composition of exported material on deep POC fluxes and transfer efficiency in CCSM-BEC, we examine the relationship between POC flux at $2000 \mathrm{~m}\left(F_{\mathrm{POC}}^{2000 \mathrm{~m}}\right)$ and transfer efficiency 

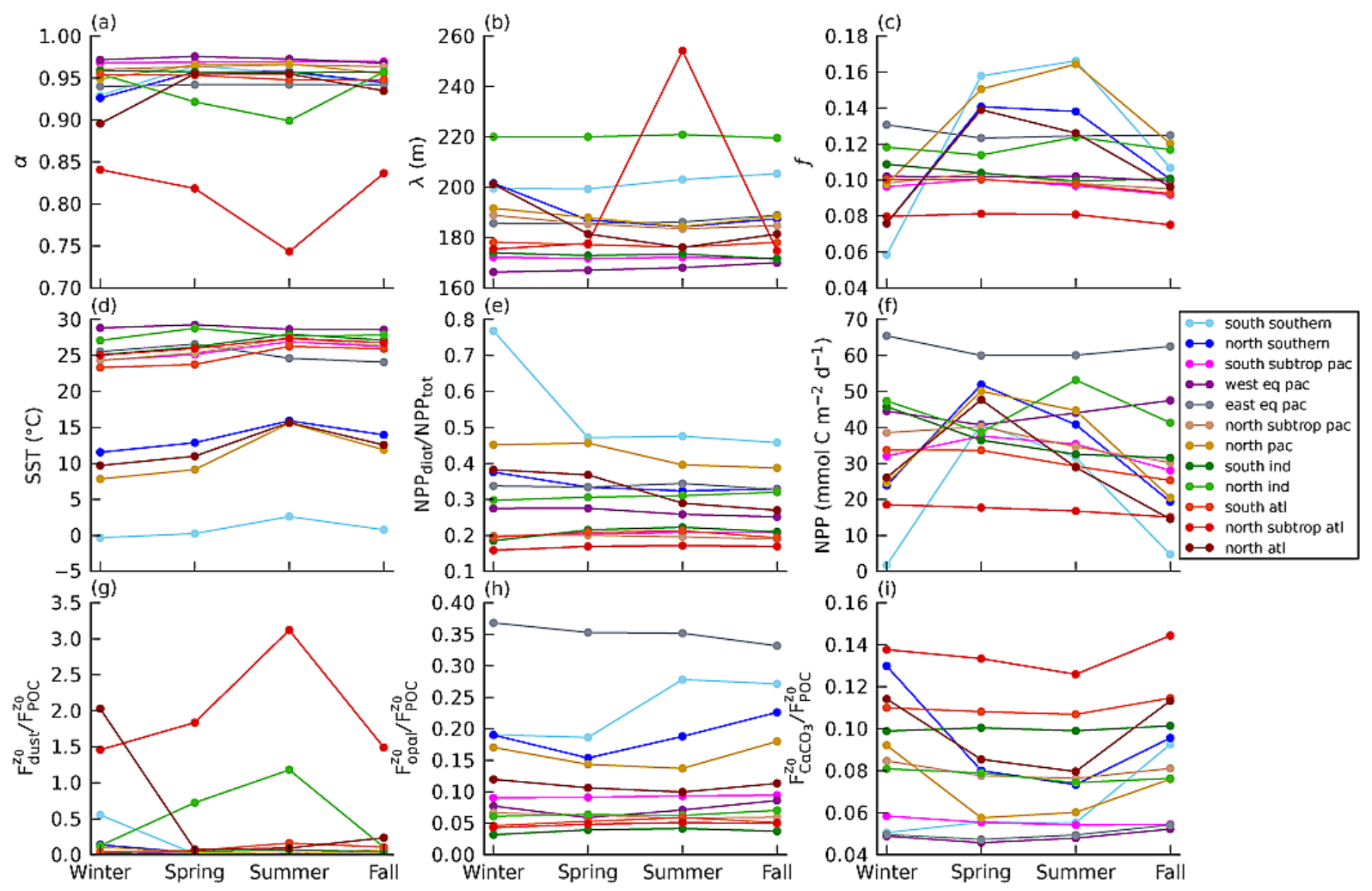

Fig. 6. Annual cycle of regional averages of estimated values of $\alpha(\mathbf{a}), \lambda(\mathbf{b}), f(\mathbf{c})$, sea surface temperature (d), the ratio of vertically integrated NPP by diatoms to total NPP (e), total NPP (f), and the ratio of dust (g), opal (h) and $\mathrm{CaCO}_{3}$ (i) flux to POC flux at export depth $\left(z_{0}\right)$. Line colors correspond to the colors of the CCSM-BEC domain regions shown in Fig. 1.

$\left(F_{\mathrm{POC}}^{2000 \mathrm{~m}} / F_{\mathrm{POC}}^{z_{0}}\right)$ with temperature, NPP, the relative contribution of diatoms to total NPP, mineral ballast export, and the ratios of mineral ballast export to POC export using stepwise multivariate linear regression analysis (MLR). The analysis is done using annual means of the different fields and thus focuses on spatial variation. The results of the stepwise MLR for standardized POC flux at $2000 \mathrm{~m}$ from CCSM-BEC are shown in Table 3. In CCSM-BEC, the variation in POC flux at $2000 \mathrm{~m}$ is well explained by the mineral ballast export $\left(r^{2}>0.98\right)$. Opal export has the highest partial regression coefficient and it alone explains over $50 \%$ of the variability in the POC flux at $2000 \mathrm{~m}$. Removal of temperature and NPP from the regression results in virtually no change in explanatory power. Thus, in CCSM-BEC, the magnitude of deep POC flux is mainly controlled by the mineral ballast export and is strongly influenced by opal export.

Similar analysis for the standardized transfer efficiency $\left(F_{\mathrm{POC}}^{2000 \mathrm{~m}} / F_{\mathrm{POC}}^{z_{0}}\right)$ against the standardized ratios of primary production by diatoms to total primary production and of dust, opal and $\mathrm{CaCO}_{3}$ flux to POC flux at the export depth (Table 4, upper part) shows that the dust content of the exported material has the strongest influence on transfer efficiency in CCSM-BEC, explaining over $90 \%$ of its variation. However, strong atmospheric dust deposition is generally re- stricted to the northern subtropical Atlantic and the northern Indian Ocean. As seen in Sect. 3.3, the strong dust signal in these regions leads to lower labile fraction in the exported material (Fig. 8g) and high transfer efficiencies (Fig. 4f) that have a disproportionately large impact on the global multivariate linear regression above (Fig. 9a). Therefore, to account for strong regional biases on the effects of dust on transfer efficiency, we repeat the stepwise multivariate linear regression analysis with those two regions removed (Fig. 9e$\mathrm{h}$, Table 4 lower part). The variation in transfer efficiency is well explained by the mineral content of the exported material $\left(r^{2}>0.9\right)$, but dust is no longer the dominant factor (Table 4). Removing temperature and/or $\frac{\mathrm{NPP}_{\text {diat }}}{\mathrm{NPP}_{\text {tot }}}$ from the analysis has a negligible effect on explanatory power, as they are well correlated with each other $(r=-0.65)$, and opal : POC and $\mathrm{CaCO}_{3}$ : $\mathrm{POC}$ flux ratios combined explain over $90 \%$ of the variation in transfer efficiency (Table 4). With the strong regional dust signal removed, the $\mathrm{CaCO}_{3}: \mathrm{POC}$ ratio in the exported material becomes the most influential factor, explaining close to $40 \%$ of the variation in transfer efficiency, followed closely by opal: POC.

The results from the regression analyses show that the spatial variation in deep POC flux and transfer efficiency in CCSM-BEC is explained by changes in mineral ballast 
Table 2. Standard partial regression coefficients and coefficients of determination $\left(r^{2}\right)$ for stepwise multivariate linear regression of standardized $\left(x^{*}=\frac{x-\bar{x}}{\sigma_{x}}\right)$ annual mean export ratio $\left(f^{*}\right)$ on standardized annual mean SST, and ratios of vertically integrated NPP by diatoms to total NPP and of dust, opal and $\mathrm{CaCO}_{3}$ flux to POC flux at the export depth $\left(z_{0}\right)$. SST is used as a proxy for water column temperature. $p<0.0000001$ for all regression coefficients.

\begin{tabular}{|c|c|c|c|c|c|c|}
\hline \multirow[b]{2}{*}{$\widehat{y}$} & \multicolumn{5}{|c|}{ partial regression coefficients } & \multirow[b]{2}{*}{$r^{2}$} \\
\hline & SST $^{*}$ & $\left(\frac{\mathrm{NPP}_{\text {diat }}}{\mathrm{NPP}_{\text {tot }}}\right)^{*}$ & $\left(\frac{F_{\text {opal }}^{z_{0}}}{F_{\mathrm{POC}}^{z_{0}}}\right)^{*}$ & $\left(\frac{F_{\mathrm{CaCO}_{3}}^{z_{0}}}{F_{\mathrm{POC}}^{z_{0}}}\right)^{*}$ & $\left(\frac{F_{\mathrm{dust}}^{z_{0}}}{F_{\mathrm{POC}}^{z_{0}}}\right)^{*}$ & \\
\hline$f^{*}$ & $\begin{array}{l}-0.307 \pm 0.021 \\
-0.309 \pm 0.020 \\
-0.306 \pm 0.020 \\
-0.192 \pm 0.019\end{array}$ & $\begin{array}{l}0.446 \pm 0.029 \\
0.444 \pm 0.029 \\
0.427 \pm 0.026 \\
0.668 \pm 0.019\end{array}$ & $\begin{array}{l}-0.028 \pm 0.020 \\
-0.028 \pm 0.020\end{array}$ & $\begin{array}{l}-0.271 \pm 0.021 \\
-0.273 \pm 0.020 \\
-0.272 \pm 0.020\end{array}$ & $-0.006 \pm 0.015$ & $\begin{array}{l}0.68213 \\
0.68210 \\
0.68172 \\
0.64433\end{array}$ \\
\hline
\end{tabular}

Table 3. Standard partial regression coefficients and coefficients of determination $\left(r^{2}\right)$ for stepwise multivariate linear regression of standardized $\left(x^{*}=\frac{x-\bar{x}}{\sigma_{x}}\right)$ POC flux at $2000 \mathrm{~m}\left(\mathrm{~F}_{\mathrm{POC}}^{2000 \mathrm{~m} *}\right)$ on standardized mean water column temperature for the upper $2000 \mathrm{~m}(\bar{T})$, vertically integrated NPP, and mineral ballast fluxes at export depth $\left(z_{0}\right) . p<0.0000001$ for all regression coefficients.

\begin{tabular}{lcccccc}
\hline \multirow{5}{*}{$\hat{y}$} & \multicolumn{5}{c}{ partial regression coefficients } & \\
\cline { 2 - 6 } & $\bar{T}^{*}$ & $\mathrm{NPP}^{*}$ & $F_{\text {dust }}^{z_{0} *}$ & $F_{\mathrm{CaCO}_{3}}^{z_{0}^{*}}$ & $F_{\text {opal }}^{z_{0} *}$ & $r^{2}$ \\
\hline \multirow{2}{*}{$0.020 \pm 0.004$} & $0.049 \pm 0.006$ & $0.381 \pm 0.003$ & $0.446 \pm 0.004$ & $0.703 \pm 0.005$ & 0.987 \\
$F_{\text {POC }}^{2000 \mathrm{~m} *}$ & & $0.068 \pm 0.005$ & $0.385 \pm 0.003$ & $0.441 \pm 0.004$ & $0.690 \pm 0.004$ & 0.987 \\
& & & $0.383 \pm 0.003$ & $0.480 \pm 0.003$ & $0.717 \pm 0.003$ & 0.985 \\
& & & $0.515 \pm 0.006$ & $0.665 \pm 0.006$ & 0.841 \\
& & & & $0.765 \pm 0.009$ & 0.586 \\
\hline
\end{tabular}

Table 4. Standard partial regression coefficients and coefficients of determination $\left(r^{2}\right)$ for stepwise multivariate linear regression of standardized $\left(x^{*}=\frac{x-\bar{x}}{\sigma_{x}}\right)$ transfer efficiency $\left(\mathrm{F}_{\mathrm{POC}}^{2000 \mathrm{~m}} / \mathrm{F}_{\mathrm{POC}}^{\mathrm{Z}_{0}}\right)$ on standardized mean water column temperature for the upper $2000 \mathrm{~m}(\overline{\mathrm{T}})$, ratios of vertically integrated NPP by diatoms to total NPP and of dust, opal and $\mathrm{CaCO}_{3}$ flux to POC flux at the export depth $\left(z_{0}\right) . p<0.0000001$ for all regression coefficients. The upper part of the table shows the coefficients obtained including all model domain regions in the analysis. The lower part of the table shows the coefficients obtained when the northern subtropical Atlantic and northern Indian Ocean regions are removed from the analysis.

\begin{tabular}{|c|c|c|c|c|c|c|}
\hline \multirow[b]{2}{*}{$\widehat{y}$} & \multicolumn{5}{|c|}{ partial regression coefficients } & \multirow[b]{2}{*}{$r^{2}$} \\
\hline & $\overline{\mathrm{T}}^{*}$ & $\left(\frac{\mathrm{NPP}_{\text {diat }}}{\mathrm{NPP}_{\text {tot }}}\right)^{*}$ & $\left(\frac{F_{\text {opal }}^{z_{0}}}{F_{\mathrm{POC}}^{z_{0}}}\right)^{*}$ & $\left(\frac{F_{\mathrm{CaCO}_{3}}^{z_{0}}}{F_{\mathrm{POC}}^{z_{0}}}\right)^{*}$ & $\left(\frac{F_{\text {dust }}^{z_{0}}}{F_{\mathrm{POC}}^{z_{0}}}\right)^{*}$ & \\
\hline \multirow{13}{*}{$\left(\frac{\mathrm{F}_{\mathrm{POC}}^{2000 \mathrm{~m}}}{\mathrm{~F}_{\mathrm{POC}}^{Z_{0}}}\right)^{*}$} & $0.034 \pm 0.003$ & $-0.005 \pm 0.004$ & $0.261 \pm 0.003$ & $0.288 \pm 0.003$ & $0.898 \pm 0.002$ & 0.995 \\
\hline & $0.032 \pm 0.002$ & & $0.263 \pm 0.003$ & $0.286 \pm 0.002$ & $0.899 \pm 0.002$ & 0.995 \\
\hline & & $-0.020 \pm 0.002$ & $0.254 \pm 0.001$ & $0.275 \pm 0.001$ & $0.903 \pm 0.001$ & 0.994 \\
\hline & & & $0.243 \pm 0.002$ & $0.283 \pm 0.002$ & $0.903 \pm 0.002$ & 0.994 \\
\hline & & & & $0.173 \pm 0.003$ & $0.899 \pm 0.003$ & 0.947 \\
\hline & & & & & $0.960 \pm 0.004$ & 0.921 \\
\hline & $0.095 \pm 0.006$ & $0.002 \pm 0.009$ & $0.888 \pm 0.006$ & $0.896 \pm 0.006$ & $0.239 \pm 0.005$ & 0.977 \\
\hline & $0.094 \pm 0.005$ & & $0.888 \pm 0.006$ & $0.895 \pm 0.005$ & $0.240 \pm 0.005$ & 0.977 \\
\hline & & $-0.076 \pm 0.004$ & $0.875 \pm 0.003$ & $0.854 \pm 0.003$ & $0.248 \pm 0.003$ & 0.974 \\
\hline & & & $0.832 \pm 0.003$ & $0.884 \pm 0.003$ & $0.242 \pm 0.003$ & 0.971 \\
\hline & & & $0.812 \pm 0.004$ & $0.970 \pm 0.004$ & & 0.922 \\
\hline & & & & $0.551 \pm 0.012$ & $0.177 \pm 0.012$ & 0.411 \\
\hline & & & & $0.620 \pm 0.011$ & & 0.385 \\
\hline
\end{tabular}



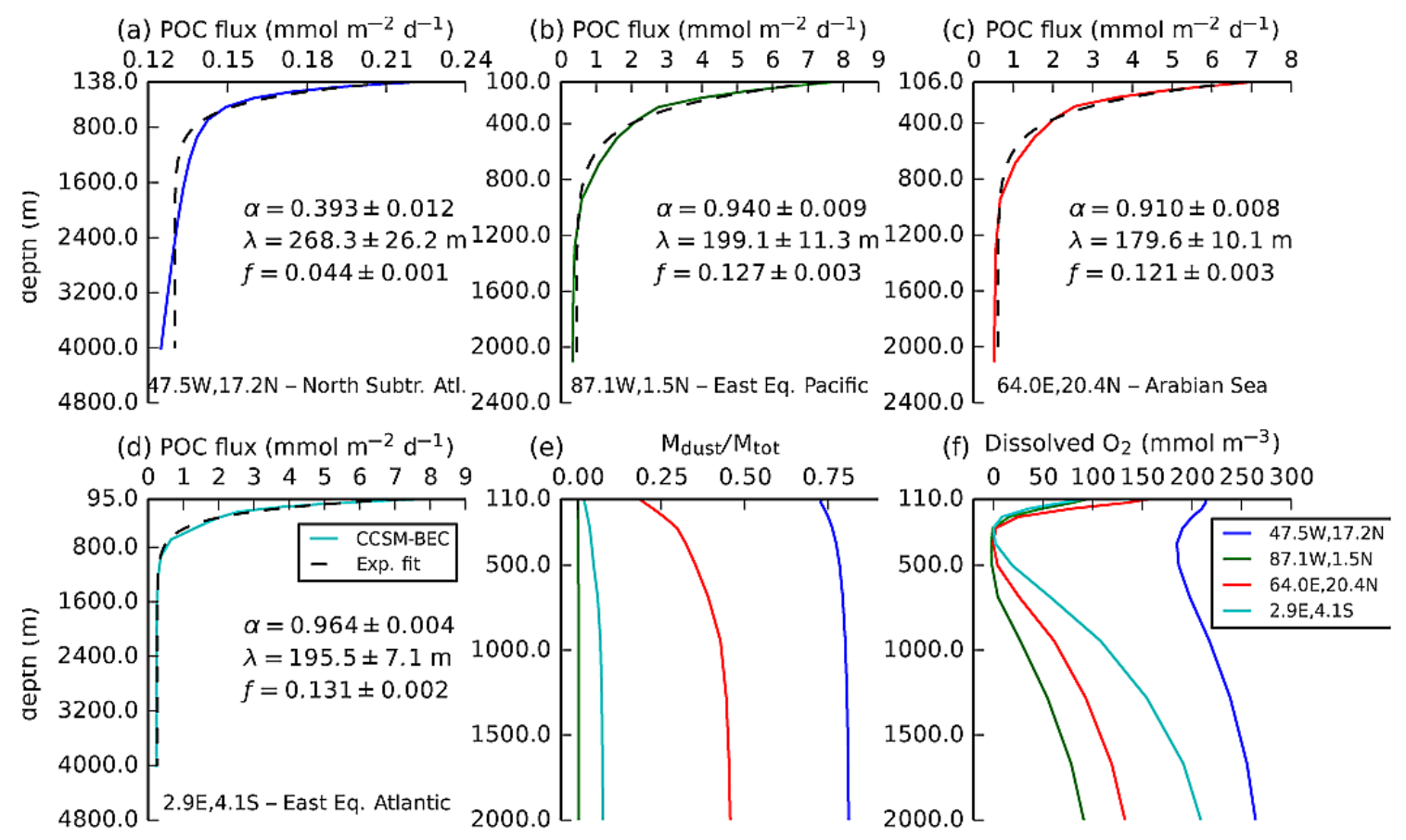

Fig. 7. (a-d) show vertical profiles of POC flux at the locations marked in Fig. 5 where the errors for the exponential model are relatively large compared to the rest of the global ocean. The solid lines represent the POC flux from CCSM-BEC, and the dashed lines show the exponential fit (Eq. 1). The estimated values of $\alpha, \lambda$ and $f$ and their $95 \%$ confidence intervals are also shown for each location. (e) and (f) show the mass flux $(M)$ ratio $\left(\mathrm{g} \mathrm{m}^{-2} \mathrm{~d}^{-1} / \mathrm{g} \mathrm{m}^{-2} \mathrm{~d}^{-1}\right)$ of sinking dust to total particulate sinking material and dissolved oxygen from CCSM-BEC, respectively, at the same locations shown in (a-d). The color of the solid lines corresponds to the color of the circles marking the location of the profiles in Fig. 5.

export and their ratios to POC export, respectively. However, while the absolute flux is strongly influenced by opal export, transfer efficiency is mostly a function of dust and $\mathrm{CaCO}_{3}$ content of exported material. The reason for the weaker opal control on transfer efficiency is that opal flux (diatom relative abundance) is well correlated with NPP (and absolute fluxes) but the ballasting effect by opal is much weaker due to its shorter remineralization length scale and strong temperature dependence. In addition, opal-rich regions are generally characterized by strong seasonality in NPP (Fig. 10b) and thus high variability in transfer efficiency, while $\mathrm{CaCO}_{3}$ and dust-rich areas tend to be more stable, with lower NPP and higher mineral : POC ratios (Fig. 10c), and the remineralization length scales for dust and $\mathrm{CaCO}_{3}$ are significantly longer than that for opal (Table 7 in Appendix A1). Therefore, although opal export explains most of the variation in absolute POC fluxes at depth, $\mathrm{CaCO}_{3}$ and dust are better predictors of transfer efficiency. In CCSM-BEC, ecosystem structure $\left(\frac{\mathrm{NPP}_{\text {diat }}}{\mathrm{NPP}_{\text {tot }}}\right)$ does not have a significant influence on transfer efficiency. Nevertheless, the negative regression coefficients for $\frac{\mathrm{NPP}_{\text {diat }}}{\mathrm{NP}_{\text {tot }}}$ in both regression analyses (Table 4) indicate that, in CCSM-BEC, transfer efficiency is inversely correlated with the relative contribution of diatoms to total NPP. This is consistent with the generally opposing spatial patterns of transfer efficiency and export ratio seen in Fig. 4, as ecosystem struc- ture is the primary factor driving the variability in export ratio (Sect. 3.3).

\section{Discussion}

Estimates of global $\mathrm{POC}$ export range from $4 \mathrm{PgCyr}^{-1}$ (Henson et al., 2011) to $\approx 21 \mathrm{PgCyr}^{-1}$ (Laws et al. (2000) using the model of Eppley and Peterson (1979)), with values clustering around either $5 \mathrm{Pg} \mathrm{Cyr}^{-1}$ (Moore et al., 2004; Lutz et al., 2007; Honjo et al., 2008; Henson et al., 2011, 2012b) or $10 \mathrm{PgC}^{-1}$ (Laws et al., 2000; Schlitzer, 2004; Gehlen et al., 2006; Dunne et al., 2007; Laws et al., 2011) (Table 5). Similarly, global mean export ratio computations vary around $\approx 10 \%$ and $\approx 20 \%$ (Table 5 ). Part of the variation in global export estimates in Table 5 is a result of different definitions of export depth. Most studies use a fixed export depth of $\approx 100 \mathrm{~m}$ or define export depth as the maximum of either the euphotic zone or mixed layer depths. Shallower export depths result in higher export estimates and vice versa. We expect the use of a fixed export depth of $\approx 100 \mathrm{~m}$ to produce lower global export estimates compared to studies using a spatially/temporally varying export depth due to the higher magnitude of the underestimation bias in productive, higher latitude regions where the export depth is significantly shallower than $100 \mathrm{~m}$. CCSM-BEC's estimates of 


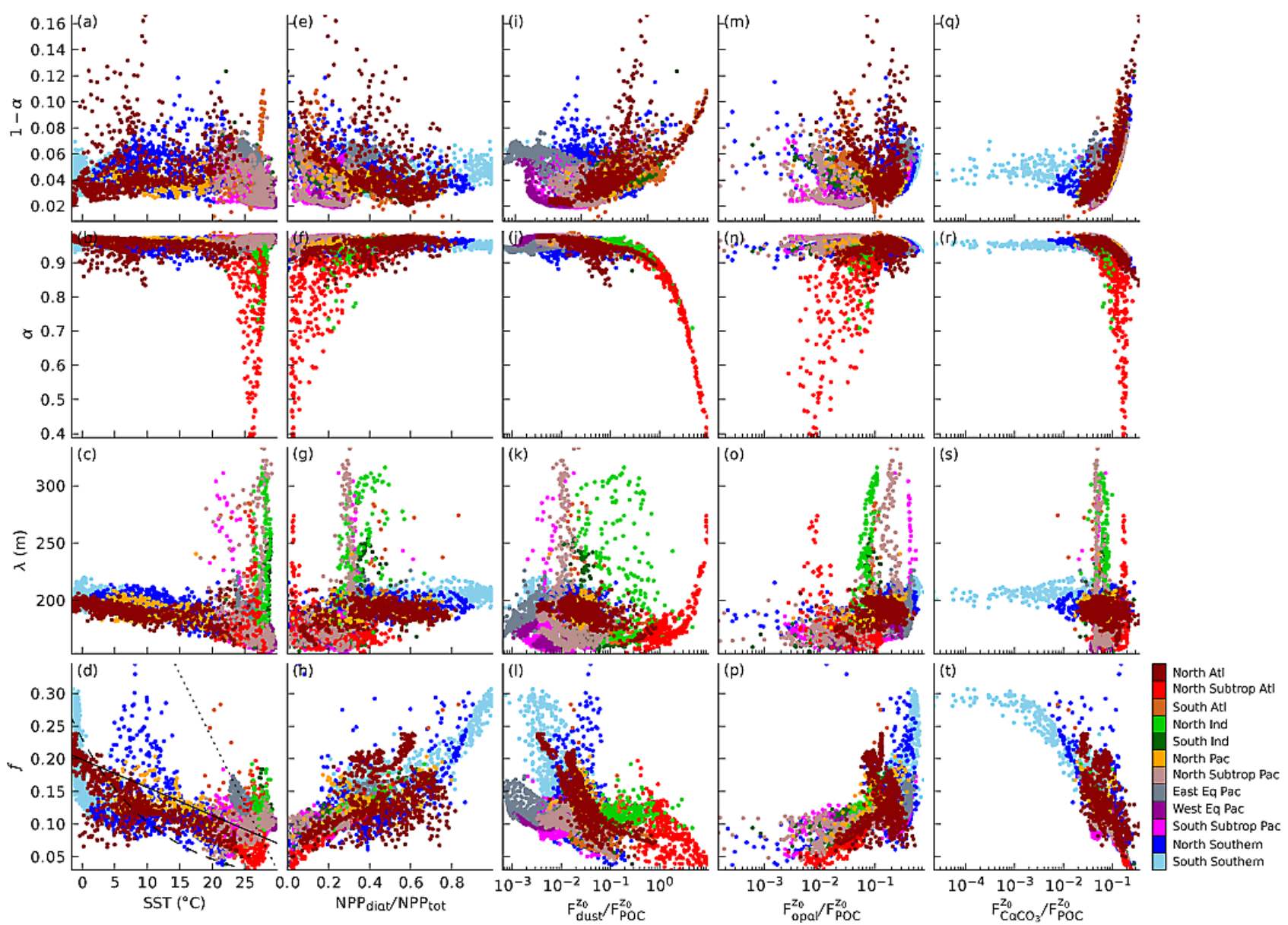

Fig. 8. $1-\alpha, \alpha, \lambda$ and $f$ obtained from fitting Eq. (1) to CCSM-BEC annual mean POC flux profiles and NPP plotted against annual means of sea surface temperature (SST) (a-d), ratio of vertically integrated NPP by diatoms to total NPP (e-h) and the ratio of dust (i-l), opal (m-p) and $\mathrm{CaCO}_{3}(\mathbf{q}-\mathbf{t})$ flux to POC flux at $z_{0}$ in CCSM-BEC. $1-\alpha$ is plotted with the regions of high atmospheric dust deposition (northern subtropical Atlantic and northern Indian Ocean) removed. Points are colored according to model domain region (Fig. 1). In (d), the solid black line shows the type II linear regression between SST and estimated $f$ values (correlation coefficient $r=-0.61$, slope $b=$ $-0.00427 \pm 9.07 \times 10^{-5}$ ), and the dashed and dotted lines show the $f$ ratio as function of SST relationships of Henson et al. (2011) and Laws et al. (2000), respectively.

global POC export (6.04 $\left.\mathrm{Pg} \mathrm{Cyr}^{-1}\right)$ and export ratio (12.9\%) are consistent with those in the first group. Different experiments with CCSM-BEC using different types of forcing produce global $\mathrm{POC}$ exports and export ratios in the range 5.5-6.3 $\mathrm{PgC}^{-1}$ and $11.5-12.9 \%$, respectively, which are close to those obtained by Moore et al. (2004) with an earlier version of CCSM-BEC. Global POC export estimates from the parameterizations shown in Fig. 3 vary between 2.23 and $7.73 \mathrm{PgCyr}^{-1}(3.8 \% \leq f \leq 16.9 \%)$ but most values are in the $4-5.5 \mathrm{PgCyr}^{-1}(6.7 \% \leq f \leq 10.8 \%)$ range (Table 6), which also makes them consistent with CCSM-BEC and other studies in the first group. The ${ }^{15} \mathrm{~N}$ isotope-based global export estimate of Laws et al. (2000) (11.1 $\left.\mathrm{PgC} \mathrm{yr}^{-1}, 21 \%\right)$ includes both DOC and POC, and is most likely an overestimation, as it does not account for potentially large biases due to significant levels of nitrification in the upper ocean (Yool et al., 2007).

The studies shown in Table 5 have their own sources of bias and uncertainty, and many are based on algorithms derived from or calibrated with sparse in situ data. It is clear from the range of estimates that in situ observations do not provide the necessary resolution to evaluate export estimates by the different methods or constrain particle flux parameterizations, which can lead to significant differences in global estimates (Gehlen et al. (2006), Table 5). Extrapolating point measurements (Fig. 1) to compute global means or integrals implies a fair amount of spatial and temporal homogeneity. The impact of spatial variability on estimates of global export and export ratios is evident in the comparison of the results from the global and regional exponential models in Table 6 . Using satellite NPP, the export and export ratio estimates 


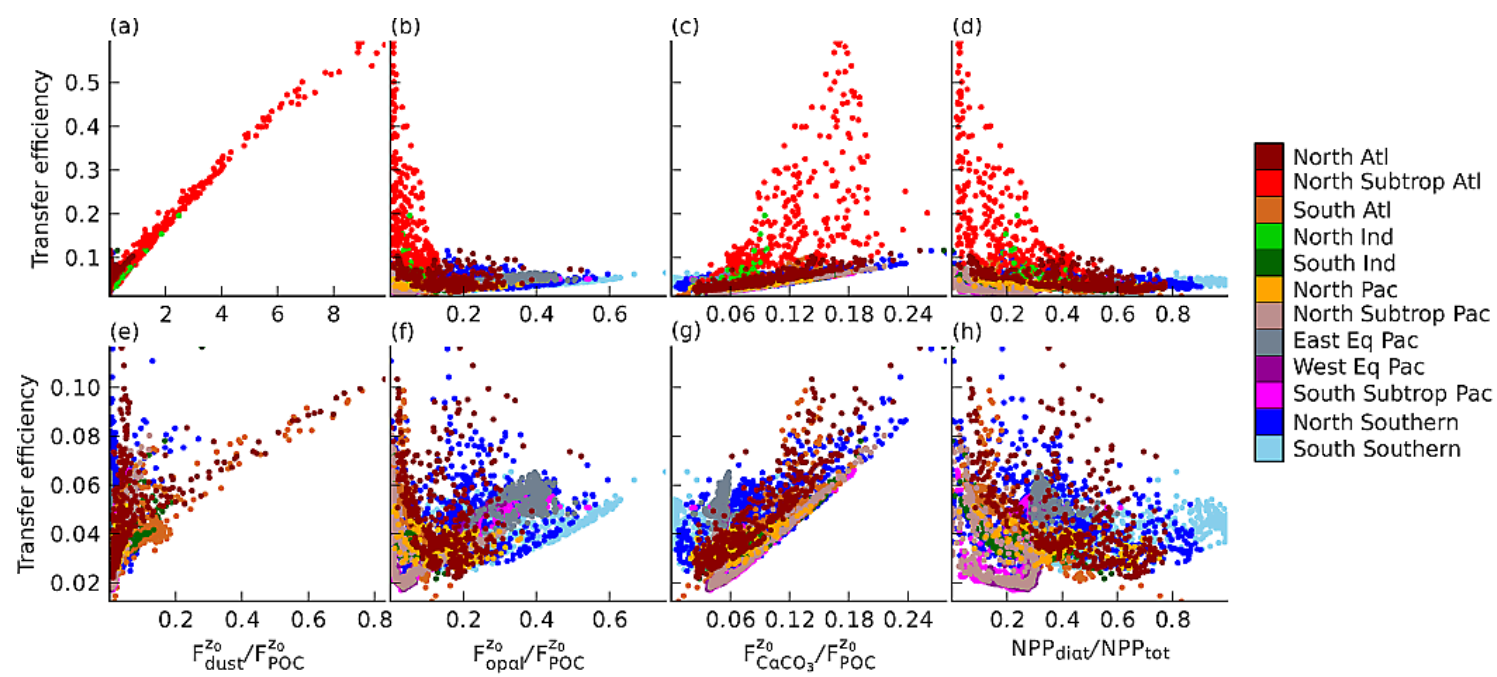

Fig. 9. Transfer efficiency (ratio of POC flux at $2000 \mathrm{~m}$ to $\mathrm{POC}$ flux at $\left.z_{0}\right)$ plotted against the ratio of dust $(\mathbf{a}, \mathbf{e})$, opal $(\mathbf{b}, \mathbf{f})$ and $\mathrm{CaCO} 3(\mathbf{c}$, g) fluxes to POC flux at export depth $\left(z_{0}\right)$, and the ratio of vertically integrated NPP by diatoms to total NPP (d, h). In (e-h), the regions of high atmospheric dust deposition (northern subtropical Atlantic and northern Indian Ocean) have been removed.
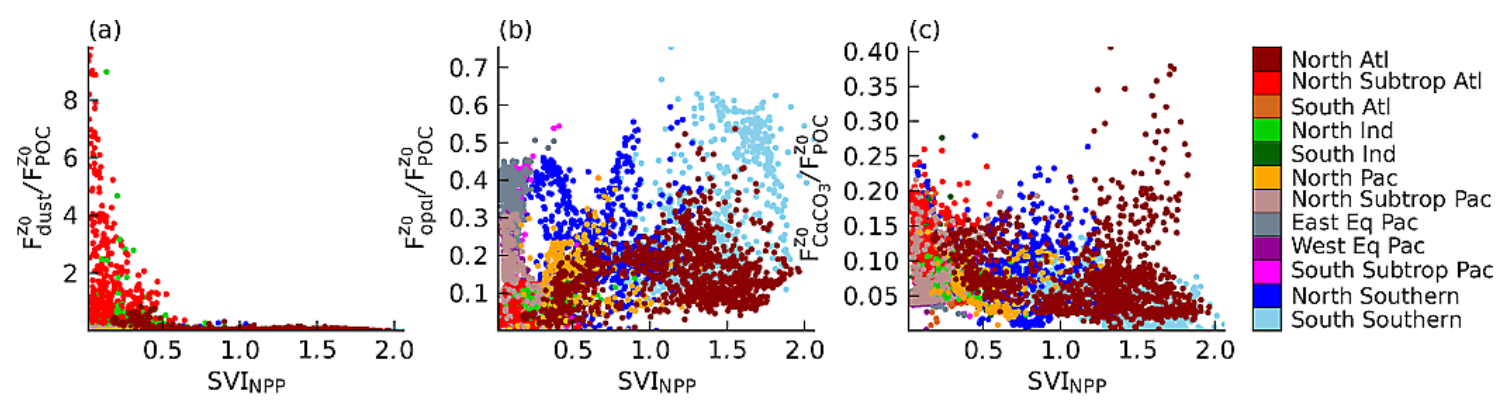

Fig. 10. Seasonal variation index for NPP $\left(\mathrm{SVI}_{\mathrm{NPP}}\right)$ plotted against the ratios of (a) dust, (b) opal and (c) $\mathrm{CaCO}_{3}$ flux to POC flux at the

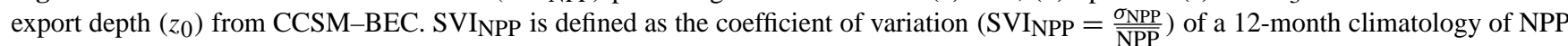
from CCSM-BEC.

from the regional exponential model are more than double those of the global model. Compounding the problem are the relatively large uncertainties associated with sediment trap data, particularly from shallow traps $(<1000 \mathrm{~m})$.

While there is some agreement regarding estimates of global export and mean export ratios, there are few independent estimates of global transfer efficiency (Table 5), defined here as as the ratio of POC flux at $2000 \mathrm{~m}$ to export flux. The transfer efficiency obtained from the Martin et al. (1987) power law $\left(F=F_{z_{0}}\left(\frac{z}{z_{0}}\right)^{b}\right)$ with $z_{0}=110.4 \mathrm{~m}$ (CCSM-BEC global mean) and $b=-0.858(8.3 \%)$, is in good agreement with the sediment trap based estimate of Honjo et al. (2008) (7.6\%). However, this is not surprising, as Honjo et al. (2008) used the Martin curve (with $b=-0.858$ ) to normalize the POC fluxes to $2000 \mathrm{~m}$ and compute transfer efficiencies. Using the Lutz et al. (2007) model in combination with an export algorithm calibrated with sediment trap data and satellite derived NPP, Henson et al. (2012b) estimates mean global transfer efficiency as
$19 \%$ (Table 5). The global area-weighted mean transfer efficiency in CCSM-BEC (5.5\%) is significantly lower than those from Henson et al. (2012b), and the parameterizations shown in Fig. 3, which range between 22.8 and 38.3\% (Table 6). The difference can be attributed to differences in formulation as well as the difference in complexity between CCSM-BEC's vertical particle flux parameterization and that of the other models. As we saw in Sect. 3.3, CCSM-BEC's complexity translates into a wide range of variation in labile fraction, remineralization length scales and export ratios (Figs. 5a, c, e and 8) that allow it to simulate widely different POC flux regimes. By contrast, the simpler parameterizations in the regional exponential and Lutz models have a more uniform parameter space, resulting in more spatially homogeneous POC flux profiles and transfer efficiency fields and thus significantly different global estimates. The four parameterizations of the exponential model (global, regional, satellite, and CCSM-BEC NPP) also tend to underestimate shallow fluxes and overestimate deep fluxes (Fig. 3b-h), 
Table 5. Global annual export and global mean export ratios and transfer efficiencies from other studies in the literature. The transfer efficiency for Martin et al. (1987) was estimated using an export depth equal to the global mean for CCSM-BEC $\left(T_{\text {eff }}=\right.$ $100\left(\frac{2000}{110.4}\right)^{-0.858}$ ). The Laws et al. (2000) estimate is for total export (POC + DOC). The export ratios $(f)$ between parentheses were estimated from global POC exports assuming global NPP of $51 \mathrm{Pg} \mathrm{C} \mathrm{yr}^{-1}$ (Carr et al., 2006).

\begin{tabular}{lrrr}
\hline study & $\begin{array}{r}\text { export } \\
\left(\mathrm{Pg} \mathrm{Cyr}^{-1}\right)\end{array}$ & $\begin{array}{r}f \\
(\%)\end{array}$ & $\begin{array}{r}T_{\text {eff }} \\
(\%)\end{array}$ \\
\hline Laws et al. (2000) & 11.1 & 21 & \\
Laws et al. (2011) & $9.23-13.24$ & $19.1-27.5$ & \\
Schlitzer (2004) & 9.6 & $(18.8)$ & \\
Gehlen et al. (2006) & $5-10$ & $13.5-28.6$ & \\
Dunne et al. (2007) & 9.6 & $(18.8)$ & \\
Eppley and Peterson (1979) & 4.7 & 20 & \\
Moore et al. (2004) & 5.8 & 8.3 & \\
Lutz et al. (2007) & 4.6 & $(9)$ & \\
Honjo et al. (2008) & 5.7 & 16.3 & 7.6 \\
Henson et al. (2011, 2012b) & 4 & 10 & 19 \\
Martin et al. (1987) & & & 8.3 \\
\hline
\end{tabular}

compared to CCSM-BEC (Sect. 3.1). These biases lead to an overestimation of transfer efficiency that is consistent with the results shown in Table 6 . The difference in transfer efficiency between CCSM-BEC and the simpler models also highlights the effect of spatial variability on global budgets. As the number and range of estimates in Table 5 shows, estimates of transfer efficiency in the ocean remain largely unconstrained despite significant efforts by observational scientists.

Although CCSM-BEC's particle flux model is fundamentally based on the ballast hypothesis (Armstrong et al., 2002), the vertical flux of POC to depth in CCSM-BEC is the result of the interaction of mineral ballast effects, environmental and biogeochemical factors, and ecosystem dynamics. The temperature dependence of the POC remineralization length scale is modulated by denitrification under low $\mathrm{O}_{2}$ concentrations and lithogenic (dust) fluxes. Export ratio is governed by diatom relative abundance while degradability of exported material is mainly influenced by dust and $\mathrm{CaCO}_{3}$ content. Transfer efficiency in the model is primarily controlled by dust and $\mathrm{CaCO}_{3}$, and, to a lesser extent, opal content of the exported material. The relative importance of the different ballast minerals in controlling transfer efficiency is the result of their respective remineralization length scales and their local supply or production in relation to local NPP. Thus, oligotrophic regions with high calcification and/or dust deposition (longer length scale) will have higher transfer efficiency than productive, opal-rich (shorter length scale) regions. Ecosystem structure does not affect transfer efficiency directly, but its indirect effect is evident in the inverse correlation between diatom relative abundance and transfer effi- ciency (Table 4) and the generally opposing spatial patterns of export ratio and transfer efficiency (Fig. 4e, f). A similar relationship between ecosystem structure (diatom relative abundance), export ratio and transfer efficiency was found by François et al. (2002) and Henson et al. (2012b). François et al. (2002), analyzing data from deep (>2000 m) sediment traps, found that transfer efficiency is primarily driven by the $\mathrm{CaCO}_{3}$ content of sinking particles, and attributed the absence of a ballasting effect by opal to an ecosystem or "packaging" effect that changes the lability of sinking particles and counteracts the ballasting effect of opal. Henson et al. (2012b), on the other hand, concluded, based on satellitederived algorithms calibrated with sediment trap data, that transfer efficiency is mainly driven by community structure (inversely correlated with diatom relative abundance). Comparison of our results with François et al. (2002) and Henson et al. (2012b) shows that although the three studies show similar relationships between ecosystem structure and transfer efficiency, different methodologies, assumptions and approximations can produce significantly different correlations between specific factors. In addition, many of the factors are not truly independent; biomineral ballast composition is inextricably linked to community structure (see Sect. 3.3, Table 2), and an effect akin to ecosystem control of transfer efficiency can be achieved with a ballast-based model. Therefore, it is difficult to differentiate between ecosystem (community structure) and ballast control of transfer efficiency. Dust is distinct from $\mathrm{CaCO}_{3}$ and opal in that it does not have a biological source, and therefore its ballasting effects should be more easily distinguishable from community structure effects.

Lithogenic material is an important control of transfer efficiency in CCSM-BEC. Dunne et al. (2007), using a combination of algorithms that connect satellite-estimated NPP to particulate fluxes through the water column to the sediments, also concluded that lithogenic material plays an important role in the transport of POC to the deep ocean, particularly in low-productivity areas, accounting for close to $50 \%$ of the total POC flux to the sea floor. In the northern subtropical Atlantic, the combination of elevated dust deposition and low NPP produces high dust: POC ratios which in turn result in low labile fraction and long remineralization length scale and the highest transfer efficiencies in CCSMBEC (Fig. 4f). Klaas and Archer (2002) also found that the magnitude of the POC flux to deep $(>3000 \mathrm{~m})$ sediment traps is mainly a function of the $\mathrm{CaCO}_{3}$ and lithogenic content of the sinking particles. François et al. (2002), analyzing a different subset of the same data, concluded that lithogenic material does not have a significant effect on transfer efficiency. However, their conclusion is based on data from 68 sediment traps, few of which are located in regions of strong lithogenic influence (northern subtropical Atlantic). Our results, on the other hand, are from a model but cover a wide range of environments and flux regimes. The effect of dust on transfer efficiency in CCSM-BEC has a strong regional bias 
Table 6. Global annual POC export and area-weighted global mean export ratios $\left(f=F_{\mathrm{POC}}^{z_{0}} / \mathrm{NPP} \times 100\right)$ and transfer efficiencies $\left(T_{\mathrm{eff}}=\right.$ $\left.F_{\text {POC }}^{2000 \mathrm{~m}} / F_{\text {POC }}^{z_{0}} \times 100\right)$ for the eight POC flux models shown in Fig. 3. The $95 \%$ confidence interval for the global export estimates from the different models were computed using the bootstrap method with 10000 samples drawn randomly with replacement.

\begin{tabular}{lllrcc}
\hline model & input NPP & spatial variation (lon $\times$ lat) & export $\left(\mathrm{Pg} \mathrm{C} \mathrm{yr}^{-1}\right)$ & $f(\%)$ & $T_{\text {eff }}(\%)$ \\
\hline CCSM-BEC & - & $3.6^{\circ} \times 0.8-1.8^{\circ}$ & $6.04 \pm 0.12$ & 12.9 & 5.5 \\
Lutz & satellite & $1^{\circ} \times 1^{\circ}$ & $4.17 \pm 0.06$ & 6.7 & 34.4 \\
Lutz null & satellite & None & $4.27 \pm 0.05$ & 7.3 & 38.3 \\
exponential global & satellite & None & $2.23 \pm 0.03$ & 3.8 & 23.4 \\
exponential regional & satellite & CCSM-BEC regions (Fig. 1) & $5.32 \pm 0.09$ & 8.6 & 22.8 \\
Lutz & CCSM-BEC & $3.6^{\circ} \times 0.8-1.8^{\circ}$ & $4.33 \pm 0.08$ & 10.8 & 31.3 \\
exponential global & CCSM-BEC & None & $4.78 \pm 0.06$ & 9.7 & 29.2 \\
exponential regional & CCSM-BEC & CCSM-BEC regions (Fig. 1) & $7.73 \pm 0.25$ & 16.7 & 25.4 \\
\hline
\end{tabular}

(northern subtropical Atlantic, northern Indian Ocean) and may be overestimated to some extent. The model's lithogenic coefficients are the least well constrained and at the upper end of the estimate from Klaas and Archer (2002). Another factor is that, in the current POC flux parameterization, the fraction of dust-associated $\mathrm{POC}$ is proportional to the vertical dust flux (Eqs. A5 and A14) and is given by the POC/dust mass ratio for particulate matter $\left(\omega_{\text {dust }}\right.$, Table 7$)$. This parameter does not depend on NPP and is held constant in the model. Thus, in regions of strong atmospheric dust deposition and low NPP, such as the northern subtropical Atlantic, this parameterization could lead to unrealistically high fractions of POC associated with dust and an overestimation of transfer efficiency. This is a potential weakness in the model, but we currently do not have the observational data to test it. In the regions of low dust input, transfer efficiency is mainly affected by $\mathrm{CaCO}_{3}$ content of sinking material; this result is consistent with previous studies (François et al., 2002; Klaas and Archer, 2002; Dunne et al., 2007).

The sparseness of sediment-trap data (Fig. 1) and the relatively large uncertainties associated with those observations make it difficult to constrain and evaluate POC flux to depth estimates from numerical models and satellite-based parameterizations. As a result, significantly different models and parameterizations show relatively similar skills when compared with observations (Fig. 3). CCSM-BEC's skill at reproducing POC flux estimates at sediment trap locations is equal to or better than that of other parameterizations. However, using CCSM-BEC NPP in the Lutz and exponential models results in a significant decrease in correlation between model estimates and observations (Fig. 3). Errors and biases in CCSM-BEC's NPP do not necessarily translate into lower skill for CCSM-BEC because of the complexity of CCSMBEC's vertical particle flux model. The vertical POC flux in CCSM-BEC is a function of many different factors in addition to NPP: environment, biogeochemical processes, mineral ballast, and ecosystem structure. This results in a disconnect and low correlation $(r=0.16)$ between POC flux and NPP at sediment trap locations. In the simpler parameteriza- tions of Lutz and the exponential models, POC flux is a more direct function of NPP (exponential decay of a fraction of NPP), and NPP and POC flux are more strongly correlated. Therefore, errors and biases in CCSM-BEC's NPP have a proportionally larger effect on POC flux estimates in these models.

In CCSM-BEC, transfer efficiency is mainly controlled by mineral ballast (dust and $\mathrm{CaCO}_{3}$ ) through changes in labile fraction $(\alpha)$ and remineralization length scale $(\lambda)$ of sinking POC. This effect is most pronounced in oligotrophic regions, where mineral: $\mathrm{POC}$ ratios are relatively high. In the northern and southern subtropical Atlantic gyres, in particular, strong atmospheric dust deposition in combination with low NPP produces the highest transfer efficiencies in CCSM-BEC (> $10 \%)$. However, the virtual absence of sediment trap measurements in these regions (or other oligotrophic gyres, Fig. 1) makes it difficult to evaluate these model results against observations. Model POC remineralization length scale is further modulated by temperature and $\mathrm{O}_{2}$ concentrations. More observations in OMZ regions would be of great value in quantifying and constraining the effect of low $\mathrm{O}_{2}$ concentrations on POC remineralization length scales. Export ratio in CCSM-BEC is mainly a function of phytoplankton community structure and temperature. The available sediment flux data, however, tend to be from sites located in productive areas (high-latitude, frontal and upwelling regions or near continental margins, Fig. 1), and therefore do not provide much contrast between ecological regimes; this makes it more difficult to evaluate the role of ecosystem structure on export ratios and transfer efficiency. To thoroughly evaluate and test model results and better understand the processes controlling POC flux to depth in the ocean, it is necessary to gather more observations in a wider range of ecological regimes, including oligotrophic gyres, OMZ regions, and areas under strong lithogenic influence. 
Table 7. Equation parameters' definitions and values.

\begin{tabular}{|c|c|c|c|}
\hline Parameter & Value & Units & Definition \\
\hline$T_{\text {ref }}$ & 30 & ${ }^{\circ} \mathrm{C}$ & reference temperature \\
\hline$q_{10}$ & 2 & & temperature-dependence factor \\
\hline $\mathrm{SiO}_{3} q_{10}$ & 4 & & temperature-dependence factor for particulate $\mathrm{SiO}_{3}$ remin \\
\hline $\mathrm{POC}_{q_{10}}$ & 1.12 & & temperature-dependence factor for POC remin \\
\hline$m_{\mathrm{sp}}$ & 0.1 & $d^{-1}$ & small phyto. linear mortality rate \\
\hline$m_{\text {diat }}$ & 0.1 & $d^{-1}$ & diatom linear mortality rate \\
\hline$p_{\mathrm{sp}}$ & 0.009 & $(\mathrm{mmolC})^{-1} \mathrm{~m}^{3} \mathrm{~d}^{-1}$ & small phyto. quadratic mortality rate \\
\hline$p_{\text {diat }}$ & 0.009 & $(\mathrm{mmolC})^{-1} \mathrm{~m}^{3} \mathrm{~d}^{-1}$ & diatom quadratic mortality rate \\
\hline$m_{\text {diaz }}$ & 0.16 & $\mathrm{~d}^{-1}$ & diazotrophs linear mortality rate \\
\hline$e_{\mathrm{sp}}^{\mathrm{POC}}$ & 0.22 & $(\mathrm{mmolC})^{-1}$ & small phyto. grazing factor \\
\hline$a_{\mathrm{sp}}^{\max }$ & 0.2 & $d^{-1}$ & max aggregation rate for small phyto \\
\hline$a_{\text {diat }}^{\max }$ & 0.2 & $d^{-1}$ & max aggregation rate for diatoms \\
\hline$a_{\text {diat }}^{\text {mint }}$ & 0.01 & $d^{-1}$ & min aggregation rate for diatoms \\
\hline$u_{\max }^{\text {sp }}$ & 2.75 & $d^{-1}$ & max zoo. growth rate on small phyto. at $T_{\text {ref }}$ \\
\hline$u_{\max }^{\text {diat }}$ & 2.07 & $d^{-1}$ & max zoo. growth rate on diatoms at $T_{\text {ref }}$ \\
\hline$u_{\max }^{d i a x}$ & 1.2 & $\mathrm{~d}^{-1}$ & max zoo. growth rate on diazotrophs at $T_{\text {ref }}$ \\
\hline$m_{z}$ & 0.1 & $d^{-1}$ & zoo. linear mortality rate \\
\hline$p_{z}$ & 0.45 & $(\mathrm{mmolC})^{-1} \mathrm{~m}^{3} \mathrm{~d}^{-1}$ & zoo. quadratic mortality rate \\
\hline$g$ & 1.05 & $\mathrm{mmolCm}^{-3}$ & zoo. grazing coefficient \\
\hline$f_{z}^{\text {diat }}$ & 0.81 & & scaling factor for grazing on diatoms \\
\hline$f_{\text {graz }}^{\text {diat, } \mathrm{POC}}$ & 0.26 & & fraction of diatom grazing routed to $\mathrm{POC}$ \\
\hline$f_{\text {diatloss }}^{\text {POC }}$ & 0.05 & & fraction of diatom loss routed to POC \\
\hline$f_{\text {graz }}^{\text {diaz, }}$ & 0.21 & & fraction of diazotrophs grazing routed to zoo \\
\hline$f_{\text {graz }}^{\text {diaz, }}$ POC & 0.0 & & fraction of diazotrophs grazing routed to POC \\
\hline$f_{\text {zloss }}^{\text {sp, POC }}$ & 0.06666 & & fraction of zoo. losses routed to POC when eating small phyto. \\
\hline$f_{\text {zloss }}^{\text {diat, } \mathrm{POC}}$ & 0.1333 & & fraction of zoo. losses routed to POC when eating diatoms \\
\hline$f_{\text {zloss }}^{\text {diaz, POC }}$ & 0.03333 & & fraction of zoo. losses routed to POC when eating diazotrophs \\
\hline$f_{\mathrm{graz}}^{\mathrm{CaCO}}{ }_{3}, \mathrm{POC}$ & 0.4 & & min. proportionality between $Q_{\mathrm{sp}}^{\mathrm{CaCO}_{3}}$ and grazing losses to POC \\
\hline$f_{\text {graz }}^{\text {sp, } \mathrm{POC}}$ & 0.24 & & upper limit on fraction of grazing on small phyto. routed to POC \\
\hline$f_{\mathrm{graz}}^{\mathrm{CaCO}}{ }_{3}$, remin & 0.33 & & fraction of $\mathrm{SP}_{\mathrm{CaCO}_{3}}$ grazing that is remineralized \\
\hline$M_{\mathrm{POC}}$ & 12.01 & $\mathrm{~g} \mathrm{~mol}^{-1}$ & POC molar mass \\
\hline$M_{\mathrm{CaCO}_{3}}$ & 100.09 & $\mathrm{~g} \mathrm{~mol}^{-1}$ & $\mathrm{CaCO}_{3}$ molar mass \\
\hline$M_{\mathrm{SiO}_{3}}$ & 60.08 & $\mathrm{~g} \mathrm{~mol}^{-1}$ & $\mathrm{SiO}_{3}$ molar mass \\
\hline$M_{\mathrm{Fe}}$ & 55.847 & $\mathrm{~g} \mathrm{~mol}^{-1}$ & Fe molar mass \\
\hline$\omega_{P \mathrm{CaCO}_{3}}$ & 0.07 & $\mathrm{~g} P O C\left(\mathrm{~g} \mathrm{CaCO}_{3}\right)^{-1}$ & associated $\mathrm{POC} / \mathrm{CaCO}_{3}$ mass ratio for particulate matter \\
\hline$\omega_{P \mathrm{SiO}_{3}}$ & 0.035 & $\mathrm{gPOC}\left(\mathrm{gPSiO}_{3}\right)^{-1}$ & associated $\mathrm{POC} / \mathrm{SiO}_{3}$ mass ratio for particulate matter \\
\hline$\omega_{\text {dust }}$ & 0.07 & $\mathrm{gPOC}(\mathrm{g} \text { dust })^{-1}$ & associated POC/dust mass ratio for particulate matter \\
\hline$\lambda_{\mathrm{POC}}$ & $130(260)^{*}$ & $\mathrm{~m}$ & remineralization length scale for soft POC (if $\left[\mathrm{O}_{2}\right]<4 \mathrm{mmol} \mathrm{m}^{-3}$ )* \\
\hline$\lambda \mathrm{CaCO}_{3}$ & 600 & $\mathrm{~m}$ & remineralization length scale for soft particulate $\mathrm{CaCO}_{3}$ \\
\hline$\lambda \mathrm{SiO}_{3}$ & 22 & $\mathrm{~m}$ & remineralization length scale for soft particulate $\mathrm{SiO}_{3}$ \\
\hline$\lambda_{\text {dust }}$ & 600 & $\mathrm{~m}$ & remineralization length scale for soft dust \\
\hline$\lambda_{\text {hard }}$ & $4 \times 10^{4}$ & $\mathrm{~m}$ & remineralization length scale for all hard particulate subclasses \\
\hline$f_{P \mathrm{CaCO}_{3}}^{\text {hard }}$ & 0.55 & & fraction of particulate $\mathrm{CaCO}_{3}$ production routed to the hard subclass \\
\hline$f_{\mathrm{PSiO}_{3}}^{\text {hard }}$ & 0.37 & & fraction of particulate $\mathrm{SiO}_{3}$ production routed to the hard subclass \\
\hline$f_{\text {dust }}^{\text {hard }}$ & 0.97 & & fraction of surface dust flux routed to the hard subclass \\
\hline$f_{\text {dust }}^{\text {bio }}$ & 0.02 & & fraction of surface iron dust flux that is bioavailable \\
\hline
\end{tabular}




\section{Summary and conclusions}

CCSM-BEC's particle flux model is fundamentally based on the ballast hypothesis, but the vertical flux of POC to depth in CCSM-BEC is the result of the interaction of many different processes including: mineral ballast effects, environmental and biogeochemical factors, and ecosystem dynamics. The POC remineralization length scale's dependence on temperature is modulated by denitrification under low $\mathrm{O}_{2}$ concentrations and lithogenic (dust) fluxes. Export ratios are mainly a function of diatom relative abundance and temperature, while transfer efficiency is driven primarily by dust and $\mathrm{CaCO}_{3}$, and, to a lesser extent, the opal content of the exported material. The close link between mineral ballast composition and plankton community structure results in correlations between export ratios and ballast mineral fluxes (opal and $\mathrm{CaCO}_{3}$ ), and transfer efficiency and diatom relative abundance that do not necessarily reflect ballast or direct ecosystem effects, respectively. This suggests that differentiating between ecosystem and ballast effects might be difficult in observations. CCSM-BEC's skill at reproducing sediment trap observations is equal to or better than that of other parameterizations. However, the sparseness and relatively large uncertainties of sediment trap data makes it difficult to accurately evaluate model skill. More POC flux observations, over a wider range of ecological regimes, are necessary in order to thoroughly evaluate and test model results and better understand the processes controlling POC flux to depth in the ocean.

\section{Appendix A}

\section{A1 Vertical particle flux equations}

Production of particulate organic carbon (POC), $\mathrm{CaCO}_{3}$ and opal are given by

$$
\begin{aligned}
\mathrm{POC}^{\mathrm{prod}} & =\mathrm{SP}_{\mathrm{agg}}+G_{\mathrm{sp}}^{\mathrm{POC}}+\mathrm{SP}_{\text {loss }}^{\mathrm{POC}}+\mathrm{Diat}_{\text {loss }}^{\mathrm{POC}} \\
& +\mathrm{Diat}_{\mathrm{agg}}+G_{\mathrm{diat}}^{\mathrm{POC}}+G_{\mathrm{diaz}}^{\mathrm{POC}}+Z_{\text {loss }}^{\mathrm{POC}} \\
\mathrm{PCaCO}_{3}{ }^{\mathrm{prod}} & =\left(\left(1-f_{\mathrm{graz}}^{\mathrm{CaC}_{3}, \text { remin }}\right) G_{\mathrm{sp}}+\mathrm{SP}_{\text {loss }}\right. \\
& \left.+\mathrm{SP}_{\mathrm{agg}}\right) Q_{\mathrm{sp}}^{\mathrm{CaCO}}{ }_{3} \\
P \mathrm{SiO}_{3}{ }^{\mathrm{prod}} & =\left(\left(1-f_{\mathrm{graz}}^{\mathrm{Si}, \text { remin }}\right) G_{\mathrm{diat}}+\mathrm{Diat}_{\mathrm{agg}}\right. \\
& \left.+f_{\text {diat loss }}^{\mathrm{POC}} \text { Diat }{ }_{\text {loss }}\right) Q_{\mathrm{diat}}^{\mathrm{Si}}
\end{aligned}
$$

where $Q_{\mathrm{sp}}^{\mathrm{CaCO}_{3}}$ and $Q_{\mathrm{diat}}^{\mathrm{Si}}$ are the $\mathrm{CaCO}_{3}: \mathrm{C}$ and $\mathrm{Si}: \mathrm{C}$ ratios for small phytoplankton and diatoms, respectively, the $G_{X}^{\mathrm{POC}}$ terms represent the fraction of zooplankton grazing $\left(G_{X}\right)$ on each phytoplankton group $(X=\{\mathrm{sp}$, diat, diaz $\})$ that is directed to POC, the term $X_{\text {loss }}^{\text {POC }}$ represent the fraction of linear mortality $\left(X_{\text {loss }}\right)$ for each phytoplankton functional group ( $X=\{$ sp,diat $\})$ that is directed to POC, $Z_{\text {loss }}^{\mathrm{POC}}$ represents the fraction of zooplankton total mortality $\left(Z_{\text {loss }}\right)$ that is directed to POC, and the terms $X_{\text {agg }}$ represent the quadratic mortality, or "aggregation", for each phytoplankton functional group ( $X=\{\mathrm{sp}$, diat $\})$. The expression for each of the terms in Eqs. (A1)-(A3) is shown below and the definitions and values for the parameters in those expressions are presented in Table 7:

$$
\begin{aligned}
& G_{\mathrm{sp}}=u_{\max }^{\mathrm{sp}} T_{f}\left(\frac{\mathrm{SP}_{\mathrm{C}}^{2}}{\mathrm{SP}_{\mathrm{C}}^{2}+g^{2}}\right) Z_{\mathrm{C}} ; \\
& G_{\mathrm{sp}}^{\mathrm{POC}}=G_{\mathrm{sp}} \times \operatorname{MAX}\left(f_{\mathrm{graz}}^{\mathrm{CaCO}_{3}, \mathrm{POC}} Q_{\mathrm{sp}}^{\mathrm{CaCO}_{3}},\right. \\
& \left.\operatorname{MIN}\left(e_{\mathrm{sp}}^{\mathrm{POC}} \mathrm{SP}_{\mathrm{C}}, f_{\text {graz }}^{\mathrm{sp}, \mathrm{POC}}\right)\right) \text {; } \\
& G_{\text {diat }}=u_{\max }^{\text {diat }} T_{f}\left(\frac{\text { Diat }_{\mathrm{C}}^{2}}{\text { Diat }_{\mathrm{C}}^{2}+g^{2} f_{z}^{\text {diat }}}\right) Z_{\mathrm{C}} \text {; } \\
& G_{\text {diat }}^{\mathrm{POC}}=f_{\text {graz }}^{\text {diat, }{ }^{\mathrm{POC}}} G_{\text {diat }} \text {; } \\
& G_{\mathrm{diaz}}=u_{\max }^{\operatorname{diaz}} T_{f}\left(\frac{\mathrm{Diaz}_{\mathrm{C}}^{2}}{\operatorname{Diaz}_{\mathrm{C}}^{2}+g^{2}}\right) Z_{\mathrm{C}} ; \\
& G_{\text {diaz }}^{\mathrm{POC}}=f_{\text {graz }}^{\text {diaz, }}{ }^{\mathrm{POC}} G_{\text {diaz }} \\
& \mathrm{SP}_{\text {loss }}=m_{\mathrm{sp}} \mathrm{SP}_{\mathrm{C}} \text {; } \\
& \mathrm{SP}_{\text {loss }}^{\mathrm{POC}}=Q_{\mathrm{sp}}^{\mathrm{CaCO}_{3}} \mathrm{SP}_{\text {loss }} \text {; } \\
& \text { Diat }_{\text {loss }}=m_{\text {diat }} \text { Diat }_{C} \text {; } \\
& \text { Diat }_{\text {loss }}^{\text {POC }}=f_{\text {diat loss }}^{\text {POC }} \text { Diat loss; } \\
& Z_{\text {loss }}=T_{f}\left(m_{z} Z_{\mathrm{C}}+p_{z} Z_{\mathrm{C}}^{2}\right) ; \\
& Z_{\text {loss }}^{\mathrm{POC}}=\frac{f_{\text {zloss }}^{\text {sp POC }} G_{\text {sp }}+f_{\text {zloss }}^{\text {diat } \mathrm{POC}} G_{\text {diat }}+f_{\text {zloss }}^{\text {dia, POC }} G_{\text {diaz }}}{G_{\text {sp }}+G_{\text {diat }}+G_{\text {diaz }}} Z_{\text {loss }} \\
& \mathrm{SP}_{\mathrm{agg}}=\operatorname{MIN}\left(a_{\mathrm{sp}}^{\max } \mathrm{SP}_{\mathrm{C}}, p_{\mathrm{sp}} \mathrm{SP}_{\mathrm{C}}^{2}\right) \text {; } \\
& \text { Diat }_{\text {agg }}=\operatorname{MIN}\left(a_{\text {diat }}^{\max } \operatorname{Diat}_{\mathrm{C}}, p_{\text {diat }} \operatorname{Diat}_{\mathrm{C}}^{2}\right) \text {. }
\end{aligned}
$$

$T_{f}$ is the temperature-dependency function for the ecosystem model and is defined as $T_{f}=q_{10}^{\frac{T-T_{\text {ref }}}{10}}$, and $\mathrm{SP}_{\mathrm{C}}$, Diat $_{C}$, Diaz $_{C}$ and $Z_{C}$ represent small phytoplankton, diatom, diazotrophs and zooplankton carbon concentrations $\left(\mathrm{mmolCm}^{-3}\right)$, respectively.

POC is partitioned between free and mineral-associated fractions according to the $\mathrm{POC} /$ mineral mass ratio for particulate matter $\left(\omega_{x}\right)$ for each mineral (Table 7), following:

$$
\begin{aligned}
& { }^{\text {nonfree }} \mathrm{POC}^{\text {prod }}=\omega_{\mathrm{PCaCO}_{3}} \frac{M_{\mathrm{CaCO}_{3}}}{M_{\mathrm{POC}}} P \mathrm{CaCO}_{3}{ }^{\text {prod }} \\
& +\omega_{P \mathrm{SiO}_{3}} \frac{M_{\mathrm{SiO}_{3}}}{M_{\mathrm{POC}}} \mathrm{PSiO}_{3}{ }^{\text {prod }} \\
& +\omega_{\text {dust }} \frac{\text { dust }^{\text {flux }}(z)}{\mathrm{d} z}, \\
& { }^{\text {free }} \mathrm{POC}^{\text {prod }}=\mathrm{POC}^{\text {prod }}-{ }^{\text {nonfree }} \mathrm{POC}^{\text {prod, }}
\end{aligned}
$$

The fraction of mineral-associated POC that is routed to the hard subclass is determined by the parameter $f_{x}^{\text {hard }}$ for each mineral (Table 7) and the vertical fluxes of the soft and hard fractions of particulate $\mathrm{CaCO}_{3}\left(\mathrm{PCaCO}_{3}\right)$, biogenic 
opal $\left(\mathrm{PSiO}_{3}\right)$ and dust are given by the following.

$$
\begin{aligned}
& \text { soft } \mathrm{PCaCO}_{3}{ }^{\text {flux }}(z)={ }^{\text {soft }} \mathrm{PCaCO}_{3} \mathrm{Cax}_{0} e^{-\frac{\left(z-z_{0}\right)}{\lambda P \mathrm{CaCO}_{3}}} \\
& +\left(1-f_{P \mathrm{CaCO}_{3}}^{\mathrm{hard}}\right) \int_{z_{0}}^{z} \mathrm{PCaCO}_{3}{ }^{\text {prod }} e^{-\frac{\left(z-z_{0}\right)}{\lambda P \mathrm{CaCO}_{3}}} \mathrm{~d} z \\
& \text { hard } \mathrm{PCaCO}_{3}{ }^{\text {flux }}(z)=\text { hard } P \mathrm{CaCO}_{3}^{\text {flux }} e_{0} e^{-\frac{\left(z-z_{0}\right)}{\lambda_{\text {hard }}}} \\
& +f_{P^{2} \mathrm{CaCO}_{3}}^{\mathrm{hard}} \int_{z_{0}}^{z} \mathrm{PCaCO}_{3}{ }^{\text {prod }} \mathrm{d} z \\
& { }^{\text {soft }} \mathrm{PSiO}_{3}{ }^{\text {flux }}(z)={ }^{\text {soft }} \mathrm{PSiO}_{3}^{\text {flux }} z_{0} e^{-\frac{\left(z-z_{0}\right)}{{ } \mathrm{PSiO}_{3}} T_{f}^{\mathrm{SiO}_{3}}} \\
& +\left(1-f_{\mathrm{PSiO}_{3}}^{\mathrm{hard}}\right) \int_{z_{0}}^{z} \mathrm{PSiO}_{3} \text { prod } e^{-\frac{\left(z-z_{0}\right)}{\lambda \mathrm{PSiO}_{3}} T_{f}^{\mathrm{SiO}_{3}}} \mathrm{~d} z \\
& \text { hard } \mathrm{PSiO}_{3}{ }^{\text {flux }}(z)={ }^{\text {hard }} \mathrm{PSiO}_{3} \mathrm{Six}_{0} e^{-\frac{\left(z-z_{0}\right)}{\lambda_{\text {hard }}}} \\
& +f_{\mathrm{PSiO}_{3}}^{\mathrm{hard}} \int_{z_{0}}^{z} \mathrm{PSiO}_{3}{ }^{\text {prod }} \mathrm{d} z \\
& { }^{\text {soft }} \operatorname{dust}^{\text {flux }}(z)=\left(1-f_{\text {dust }}^{\text {hard }}\right)\left(1-f_{\text {dust }}^{\text {bio }}\right) \operatorname{dust}_{z_{0}}^{\text {flux }} e^{-\frac{\left(z-z_{0}\right)}{\lambda_{\text {dust }}}} \\
& { }^{\text {hard }} \mathrm{dust}^{\text {flux }}(z)=f_{\text {dust }}^{\text {hard }}\left(1-f_{\text {dust }}^{\text {bio }}\right) \text { dust }_{z_{0}}^{\text {flux }} e^{-\frac{\left(z-z_{0}\right)}{\lambda_{\text {hard }}}}
\end{aligned}
$$

The vertical fluxes of free, associated, and total POC at depth (z) are given by the following.

$$
\begin{aligned}
{ }_{\text {free }} \operatorname{POC}^{\text {flux }}(z) & ={ }^{\text {free }} \operatorname{POC}_{z_{0}}^{\text {flux }} e^{-\frac{\left(z-z_{0}\right)}{\lambda_{\mathrm{POC}}} T_{f}^{\mathrm{POC}}} \\
& +\int_{z_{0}}^{z}{ }^{\text {free }} \mathrm{POC}^{\mathrm{prod}} e^{-\frac{\left(z-z_{0}\right)}{\lambda_{\mathrm{POC}}} T_{f}^{\mathrm{POC}}} \mathrm{d} z
\end{aligned}
$$

$$
\begin{aligned}
& { }_{\text {nonfree }} \mathrm{POC}^{\text {flux }}(z) \\
& =\omega_{\mathrm{PCaCO}_{3}} \frac{M_{\mathrm{CaCO}_{3}}}{M_{\mathrm{POC}}}\left({ }^{\text {soft }} P_{\mathrm{CaCO}_{3}}{ }^{\text {flux }}(z)+{ }^{\text {hard }} P_{\mathrm{CaCO}_{3}}{ }^{\text {flux }}(z)\right) \\
& +\omega_{\mathrm{PSiO}_{3}} \frac{M_{\mathrm{SiO}_{3}}}{M_{\mathrm{POC}}}\left({ }^{\text {soft }} \mathrm{PSiO}_{3}{ }^{\text {flux }}(z)+{ }^{\text {hard }} P_{\mathrm{SiO}_{3}}{ }^{\text {flux }}(z)\right) \\
& +\omega_{\text {dust }} \frac{1}{M_{\mathrm{POC}}}\left({ }^{\text {soft }}{ }^{\text {dust }}{ }^{\text {flux }}(z)+{ }^{\text {hard }} \text { dust }^{\text {flux }}(z)\right)
\end{aligned}
$$$$
\operatorname{POC}^{\text {flux }}(z)={ }^{\text {free }} \operatorname{POC}^{\text {flux }}(z)+{ }^{\text {nonfree }} \operatorname{POC}^{\text {flux }}(z)
$$

The temperature dependency functions for opal $\left(\mathrm{SiO}_{3}\right)$ and POC are defined as

$$
\begin{aligned}
& T_{f}^{\mathrm{SiO}_{3}}={ }^{\mathrm{SiO}_{3}} q_{10}^{\frac{T-T_{\mathrm{ref}}}{10}} \\
& T_{f}^{\mathrm{POC}}={ }^{\mathrm{POC}} q_{10}^{\frac{T-T_{\mathrm{ref}}}{10}},
\end{aligned}
$$

Remineralization is computed from conservation.

$$
\begin{aligned}
& P \mathrm{CaCO}_{3}{ }^{\text {remin }}(z)=P \mathrm{CaCO}_{3}{ }^{\operatorname{prod}}(z) \\
& +\frac{\mathrm{d}\left({ }^{\text {soft }} \mathrm{PCaCO}_{3}{ }^{\text {flux }}(z)\right)}{\mathrm{d} z} \\
& +\frac{\mathrm{d}\left({ }^{\text {hard }} P \mathrm{CaCO}_{3}{ }^{\text {flux }}(z)\right)}{\mathrm{d} z} \\
& P \mathrm{SiO}_{3}{ }^{\text {remin }}(z)=P \mathrm{SiO}_{3}{ }^{\text {prod }}(z) \\
& +\frac{\mathrm{d}\left({ }^{\text {soft }} P \mathrm{SiO}_{3}{ }^{\text {flux }}(z)\right)}{\mathrm{d} z} \\
& +\frac{\mathrm{d}\left({ }^{\text {hard }} P \mathrm{SiO}_{3}{ }^{\text {flux }}(z)\right)}{\mathrm{d} z} \\
& \operatorname{POC}^{\mathrm{remin}}(z)=\operatorname{POC}^{\text {prod }}(z) \\
& +\frac{\mathrm{d}\left({ }^{\text {free }} \text { POC }^{\text {flux }}(z)\right)}{\mathrm{d} z} \\
& +\frac{\mathrm{d}\left({ }^{\text {nonfree }} \text { POC }^{\text {flux }}(z)\right)}{\mathrm{d} z} \\
& \operatorname{dust}^{\text {remin }}(z)=\frac{\left.d \text { (soft }^{\text {dust }}{ }^{\text {flux }}(z)\right)}{\mathrm{d} z} \\
& +\frac{\mathrm{d}\left({ }^{\text {hard }} \text { dust }^{\text {flux }}(z)\right)}{d z}
\end{aligned}
$$

The parameter definitions and values for Eqs. (A1)-(A20) are shown in Table 7.

\section{A2 Exponential model}

POC flux $(F)$ is assumed to decay exponentially with depth $(z)$, following

$F(z)=F\left(z_{0}\right) e^{-\frac{1}{\lambda}\left(z-z_{0}\right)}$,

where $F\left(z_{0}\right)$ is the POC flux at export depth $z_{0}$ (export flux) and $\lambda$ is the remineralization length scale. Assuming labile $\left(\alpha_{1}\right)$ and refractory $\left(\alpha_{\mathrm{r}}\right)$ fractions, Eq. (A21) becomes

$F(z)=F\left(z_{0}\right)\left(\alpha_{1} e^{-\frac{1}{\lambda_{1}}\left(z-z_{0}\right)}+\alpha_{\mathrm{r}} e^{-\frac{1}{\lambda_{\mathrm{r}}}\left(z-z_{0}\right)}\right)$.

For large $\lambda_{\mathrm{r}}$ values, $\frac{1}{\lambda_{\mathrm{r}}} \rightarrow 0$ and Eq. (A22) becomes

$$
F(z)=F\left(z_{0}\right)\left(\alpha_{1} e^{-\frac{1}{\lambda_{1}}\left(z-z_{0}\right)}+\alpha_{\mathrm{r}}\right) .
$$

From Eq. (A23) at $z=z_{0}$, we have that $\alpha_{\mathrm{r}}=1-\alpha_{1}$. Defining export flux $F\left(z_{0}\right)$ as a fraction $(f)$ of vertically integrated net primary production (NPP) and dropping the subscripts $\left(\alpha=\alpha_{1}, \lambda=\lambda_{1}\right)$, Eq. (A23) is rewritten as

$$
F(z)=f \operatorname{NPP}\left(\alpha e^{-\frac{1}{\lambda}\left(z-z_{0}\right)}+(1-\alpha)\right) .
$$


Acknowledgements. We thank Michael Lutz for making his climatology of sediment trap observations available. Support for this work was provided by WHOI Ocean and Climate Change Institute and NSF grants OCE-0960880 and AGS-1048827.

Edited by: G. Herndl

\section{References}

Archer, D., Winguth, A., Lea, D., and Mahowald, N.: What caused the glacial/interglacial atmospheric $p \mathrm{CO}_{2}$ cycles?, Rev. Geophys., 38, 159-189, 2000.

Armstrong, R. A., Lee, C., Hedges, J. I., Honjo, S., and Wakeham, S. G.: A new, mechanistic model for organic carbon fluxes in the ocean based on the quantitative association of POC with ballast minerals, Deep-Sea Res. Pt. II, 49, 219-236, 2002.

Behrenfeld, M. J. and Falkowski, P. G.: Photosynthetic rates derived from satellite-based chlorophyll concentration, Limnol. Oceanogr., 42, 1-20, 1997.

Boyd, P. and Newton, P.: Does planktonic community structure determine downward particulate organic carbon flux in different oceanic provinces?, Deep-Sea Res. Pt. I, 46, 63-91, doi:10.1016/S0967-0637(98)00066-1, 1999.

Boyd, P. W. and Trull, T. W.: Understanding the export of biogenic particles in oceanic waters: Is there consensus?, Progr. Oceanogr., 72, 276-312, 2007.

Buesseler, K. O. and Boyd, P. W.: Shedding light on processes that control particle export and flux attenuation in the twilight zone of the open ocean, Limnol. Oceanogr., 54, 1210-1232, 2009.

Carr, M.-E., Friedrichs, M. A., Schmeltz, M., Noguchi Aita, M., Antoine, D., Arrigo, K. R., Asanuma, I., Aumont, O., Barber, R., Behrenfeld, M., Bidigare, R., Buitenhuis, E. T., Campbell, J., Ciotti, A., Dierssen, H., Dowell, M., Dunne, J., Esaias, W., Gentili, B., Gregg, W., Groom, S., Hoepffner, N., Ishizaka, J., Kameda, T., Le Quéré, C., Lohrenz, S., Marra, J., Mélin, F., Moore, K., Morel, A., Reddy, T. E., Ryan, J., Scardi, M., Smyth, T., Turpie, K., Tilstone, G., Waters, K., and Yamanaka, Y.: A comparison of global estimates of marine primary production from ocean color, Deep-Sea Res. Pt. II, 53, 741-770, 2006.

Collins, W. D., Bitz, C. M., Blackmon, M. L., Bonan, G. B., Bretherton, C. S., Carton, J. A., Chang, P., Doney, S. C., Hack, J. J., Henderson, T. B., Kiehl, J. T., Large, W. G., McKenna, D. S., Santer, B. D., and Smith, R. D.: The Community Climate System Model Version 3 (CCSM3), J. Climate, 19, 2122-2143, 2006.

Doney, S. C., Lindsay, K., Fung, I., and John, J.: Natural Variability in a Stable, 1000-Yr Global Coupled Climate-Carbon Cycle Simulation, J. Climate, 19, 3033-3054, 2006.

Doney, S. C., Yeager, S., Danabasoglu, G., Large, W. G., and McWilliams, J. C.: Mechanisms Governing Interannual Variability of Upper-Ocean Temperature in a Global Ocean Hindcast Simulation, J. Phys. Oceanogr., 37, 1918-1938, 2007.

Doney, S. C., Lima, I., Feely, R. A., Glover, D. M., Lindsay, K., Mahowald, N., Moore, J. K., and Wanninkhof, R.: Mechanisms governing interannual variability in upper-ocean inorganic carbon system and air-sea $\mathrm{CO}_{2}$ fluxes: Physical climate and atmospheric dust, Deep-Sea Res. Pt. II, 56, 640-655, 2009a.

Doney, S. C., Lima, I., Moore, J. K., Lindsay, K., Behrenfeld, M. J., Westberry, T. K., Mahowald, N., Glover, D. M., and Takahashi,
T.: Skill metrics for confronting global upper ocean ecosystembiogeochemistry models against field and remote sensing data, J. Mar. Syst., 76, 95-112, 2009 b.

Dunne, J. P., Sarmiento, J. L., and Gnanadesikan, A.: A synthesis of global particle export from the surface ocean and cycling through the ocean interior and on the seafloor, Global Biogeochem. Cy., 21, doi:10.1029/2006GB002907, 2007.

Eppley, R. W. and Peterson, B. J.: Particulate organic matter flux and planktonic new production in the deep ocean, Nature, 282, 677-680, 1979.

François, R., Honjo, S., Krishfield, R., and Manganini, S.: Factors controlling the flux of organic carbon to the bathypelagic zone of the ocean, Global Biogeochem. Cy., 16, 1087, doi:10.1029/2001GB001722, 2002.

Gehlen, M., Bopp, L., Emprin, N., Aumont, O., Heinze, C., and Ragueneau, O.: Reconciling surface ocean productivity, export fluxes and sediment composition in a global biogeochemical ocean model, Biogeosciences, 3, 521-537, doi:10.5194/bg-3521-2006, 2006.

Gent, P. R. and McWilliams, J. C.: Isopycnal Mixing in Ocean Circulation Models, J. Phys. Oceanogr., 20, 150-155, 1990.

Guidi, L., Stemmann, L., Jackson, G. A., Ibanez, F., Claustre, H., Legendre, L., Picheral, M., and Gorsky, G.: Effects of phytoplankton community on production, size, and export of large aggregates: A world-ocean analysis, Limnol. Oceanogr., 54, 19511963, 2009.

Henson, S. A., Sanders, R., Madsen, E., Morris, P. J., Le Moigne, F., and Quartly, G. D.: A reduced estimate of the strength of the ocean's biological carbon pump, Geophys. Res. Lett., 38, L04606, doi:10.1029/2011GL046735, 2011.

Henson, S., Smyth, R. L., Durkin, C. A., Li, J., Slemmons, K. E. H., and La Nafie, Y. A.: Variability in phytoplankton community structure in response to the North Atlantic Oscillation and implications for organic carbon flux, Limnol. Oceanogr., 57, 16021618, 2012a.

Henson, S. A., Sanders, R., and Madsen, E.: Global patterns in efficiency of particulate organic carbon export and transfer to the deep ocean, Global Biogeochem. Cy., 26, doi:10.1029/2011GB004099, 2012b.

Honjo, S., Manganini, S. J., Krishfield, R. A., and Francois, R.: Particulate organic carbon fluxes to the ocean interior and factors controlling the biological pump: a synthesis of global sediment trap programs since 1983, Progr. Oceanogr., 76, 217-285, 2008.

Klaas, C. and Archer, D. E.: Association of sinking organic matter with various types of mineral ballast in the deep sea: Implications for the rain ratio, Global Biogeochem. Cy., 16, 1116, doi:10.1029/2001GB001765, 2002.

Lam, P. J., Doney, S. C., and Bishop, J. K. B.: The dynamic ocean biological pump: Insights from a global compilation of particulate organic carbon, $\mathrm{CaCO}_{3}$, and opal concentration profiles from the mesopelagic, Global Biogeochem. Cy., 25, GB3009, doi:10.1029/2010GB003868, 2011.

Large, W. G., McWilliams, J. C., and Doney, S. C.: Oceanic vertical mixing: A review and a model with a nonlocal boundary layer parameterization, Rev. Geophys., 32, 363-403, 1994.

Laws, E. A., Falkowski, P. G., Smith, W. O., Ducklow, H., and McCarthy, J. J.: Temperature effects on export production in the open ocean, Global Biogeochem. Cy., 14, 1231-1246, 2000. 
Laws, E. A., D'Sa, E., and Naik, P.: Simple equations to estimate ratios of new or export production to total production from satellite-derived estimates of sea surface temperature and primary production, Limnol. Oceanogr.-Methods, 9, 593-601, 2011.

Lutz, M. J., Caldeira, K., Dunbar, R. B., and Behrenfeld, M. J.: Seasonal rhythms of net primary production and particulate organic carbon flux to depth describe the efficiency of biological pump in the global ocean, J. Geophys. Res., 112, C10011, doi:10.1029/2006JC003706, 2007.

Mahowald, N., Luo, C., del Corral, J., and Zender, C. S.: Interannual variability in atmospheric mineral aerosols from a 22-year model simulation and observational data, J. Geophys. Res.-Atmos., 108, doi:10.1029/2002JD002821, 2003.

Marshall, J., Ferrari, R., Forget, G., Maze, G., Andersson, A., Bates, N., Dewar, W., Doney, S., Fratantoni, D., Joyce, T., Straneo, F., Toole, J., Weller, R., Edson, J., Gregg, M., Kelly, K., Lozier, S., Palter, J., Lumpkin, R., Samelson, R., Skyllingstad, E., Silverthorne, K., Talley, L., and Thomas, L.: The Climode Field Campaign: Observing the Cycle of Convection and Restratification over the Gulf Stream, B. Am. Meteorol. Soc., 90, 1337-1350, 2009.

Martin, J. H., Knauer, G. A., Karl, D. M., and Broenkow, W. W.: VERTEX: carbon cycling in the northeast Pacific, Deep-Sea Res., 34, 267-285, 1987.

Moore, J. K. and Doney, S. C.: Iron availability limits the ocean nitrogen inventory stabilizing feedbacks between marine denitrification and nitrogen fixation, Global Biogeochem. Cy., 21, doi:10.1029/2006GB002762, 2007.

Moore, J. K., Doney, S. C., and Lindsay, K.: Upper ocean ecosystem dynamics and iron cycling in a global three-dimensional model, Global Biogeochem. Cy., 18, doi:10.1029/2004GB002220, 2004.

Najjar, R. G. and Keeling, R. F.: Analysis of the mean annual cycle of the dissolved oxygen anomaly in the World Ocean, J. Mar. Res., 55, 117-151, doi:10.1357/0022240973224481, 1997.
Najjar, R. G., Jin, X., Louanchi, F., Aumont, O., Caldeira, K., Doney, S. C., Dutay, J.-C., Follows, M., Gruber, N., Joos, F., Lindsay, K., Maier-Reimer, E., Matear, R. J., Matsumoto, K., Monfray, P., Mouchet, A., Orr, J. C., Plattner, G.-K., Sarmiento, J. L., Schlitzer, R., Slater, R. D., Weirig, M.-F., Yamanaka, Y., and Yool, A.: Impact of circulation on export production, dissolved organic matter, and dissolved oxygen in the ocean: Results from Phase II of the Ocean Carbon-cycle Model Intercomparison Project (OCMIP-2), Global Biogeochem. Cy., 21, doi:10.1029/2006GB002857, 2007.

Schlitzer, R.: Export production in the equatorial and North $\mathrm{Pa}-$ cific derived from dissolved oxygen, nutrient and carbon data, J. Oceanogr., 60, 53-62, 2004.

Siegenthaler, U., Stocker, T. F., Monnin, E., Lüthi, D., Schwander, J., Stauffer, B., Raynaud, D., Barnola, J.-M., Fischer, H., Masson-Delmotte, V., and Jouzel, J.: Stable Carbon CycleClimate Relationship During the Late Pleistocene, Science, 310, 1313-1317, 2005.

Volk, T. and Hoffert, M. I.: Ocean carbon pumps: Analysis of relative strengths and efficiencies in ocean-driven atmospheric $\mathrm{CO}_{2}$ changes, Geophys. Monogr. Ser., 32, 99-110, 1985.

Wilson, J. D., Barker, S., and Ridgwell, A.: Assessment of the spatial variability in particulate organic matter and mineral sinking fluxes in the ocean interior: Implications for the ballast hypothesis, Global Biogeochem. Cy., 26, doi:10.1029/2012GB004398, 2012.

Yeager, S. G., Shields, C. A., Large, W. G., and Hack, J. J.: The Low-Resolution CCSM3, J. Climate, 19, 2545-2566, 2006.

Yool, A., Martin, A. P., Fernández, C., and Clark, D. R.: The significance of nitrification for oceanic new production, Nature, 447 , 999-1002, 2007. 